\title{
Expressive language development in adolescents with Down syndrome and fragile $X$ syndrome: change over time and the role of family-related factors
}

Laura del Hoyo Soriano ${ }^{1,2^{*}}$ (D), Angela John Thurman ${ }^{1,2}$, Danielle Harvey ${ }^{3}$, Sara T. Kover ${ }^{4}$ and Leonard Abbeduto ${ }^{1,2}$

\begin{abstract}
Background: It is well known that individuals with Down syndrome (DS) or fragile X syndrome (FXS) demonstrate expressive language difficulties beginning early in childhood. It is less clear, however, whether expressive language skills change during the adolescent period in these individuals, and if any of these changes are syndrome specific. Studying this, as well as the role of maternal and family-related factors in expressive language development, may provide the foundation for efficacious interventions for adolescents with DS or FXS.

Methods: In this study, we examined expressive language trajectories, assessed through conversation and narration, in 57 adolescent males with intellectual disability (ID) (20 DS and 37 FXS) in relation to the diagnostic group (DS vs. FXS) and family-related factors (maternal IQ, maternal psychological distress, closeness in the motherchild relationship, family income, and maternal and paternal education) after adjusting for chronological age (CA) and nonverbal cognition.

Results: Changes over repeated annual assessments for males with DS or FXS were observed only during conversation, such as an increase in talkativeness, but a decrease in syntax complexity and lexical diversity. We found a diagnosis-related effect in the change over time in conversational talkativeness favoring those with FXS. Finally, a closer mother-child relationship predicted less decrease over time in lexical diversity during conversation, and participants of mothers who graduated college showed a greater increase in conversational talkativeness over time compared to those of mothers with a high school education.

Conclusions: Our results suggest that, during the adolescent period for males with DS or FXS, there is an increase in the amount of talk produced in conversational contexts, but also a decrease in the quality of the language produced. In addition, our results indicate syndrome-specificity for aspects of expressive language development and reinforce the protective role of family-related factors.
\end{abstract}

Keywords: Down syndrome, Fragile X syndrome, Longitudinal, Expressive language development, Family-related factors, Adolescence, Conversation, Narration

\footnotetext{
* Correspondence: Idelhoyo@ucdavis.edu

'The MIND Institute, University of California, Davis, 2825 50th Street, Rm 2101, Sacramento, CA 95817, USA

${ }^{2}$ Department of Psychiatry and Behavioral Sciences, University of California, Davis, Sacramento, USA

Full list of author information is available at the end of the article
}

C C The Author(s). 2020 Open Access This article is licensed under a Creative Commons Attribution 4.0 International License, which permits use, sharing, adaptation, distribution and reproduction in any medium or format, as long as you give appropriate credit to the original author(s) and the source, provide a link to the Creative Commons licence, and indicate if changes were made. The images or other third party material in this article are included in the article's Creative Commons licence, unless indicated otherwise in a credit line to the material. If material is not included in the article's Creative Commons licence and your intended use is not permitted by statutory regulation or exceeds the permitted use, you will need to obtain permission directly from the copyright holder. To view a copy of this licence, visit http://creativecommons.org/licenses/by/4.0/. The Creative Commons Public Domain Dedication waiver (http://creativecommons.org/publicdomain/zero/1.0/) applies to the data made available in this article, unless otherwise stated in a credit line to the data. 


\section{Introduction}

Down syndrome (DS) and fragile X syndrome (FXS) are the two most common genetic causes of intellectual disability (ID). DS is typically caused by an extra copy of all or part of chromosome 21 and has a prevalence of 1 in 1000 to 1 in 1100 live births [1]. FXS results from the expansion of a repetitive sequence of trinucleotides in the FMR1 gene on the long arm of the $\mathrm{X}$ chromosome [2]. Because FXS is an inherited X-linked condition, it affects more males than females, with an incidence of 1.4 per 10,000 males and 0.9 per 10,000 females [3]. Females with FXS are also, as a group, less severely affected than males, with more than $90 \%$ of males meeting criteria for ID compared to nearly $33 \%$ of females $[4,5]$. In this study, we focused on understanding the expressive language development of males with ID associated with DS or FXS, with an emphasis on both common and unique developmental patterns and mechanisms.

Language development is impaired in virtually all individuals with ID [6]. At the same time, however, there is evidence of differences in the profile of language impairments across different etiological conditions, including DS or FXS. Etiological differences are seen, for example, in the severity of delay or impairment in syntax relative to vocabulary and in the expressive versus receptive modalities [6]. Although these etiology-related profile differences can have important functional consequences for the individual and suggest variations in learning mechanisms and/or inputs, it is important to recognize that there are arguably more commonalities than differences among individuals with ID. Indeed, even in ID conditions associated with considerable heterogeneity [7], there are seldom instances of age-appropriate levels of skill in any area of language, which is not surprising given the strong association between language and cognitive development.

Although individuals with DS and those with FXS both show impairments in receptive language, these impairments tend to be consistent with expectations based on their levels of cognitive functioning [8-11]. In contrast, expressive language development typically lags behind receptive language and cognition for both individuals with DS [12] and males with FXS [13]. In addition, several studies have demonstrated that the profile of relative impairment across various areas of expressive language differs between individuals with FXS and those with DS beginning in early childhood [6, 14-16]. However, most of these studies have been based on comparisons between the diagnostic group at a single point in time and often for groups of participants representing wide age ranges $[8,15]$. Consequently, little is known about how expressive language profiles change over the course of development for individuals DS or FXS and how they compare. There is a need, therefore, for longitudinal studies in DS and in FXS, with a focus on expressive language being particularly important given the (1) greater impairments in expression than reception and (2) emergence of promising interventions for expressive language in these syndromes $[17,18]$.

Existing longitudinal studies of expressive language development in DS and in FXS samples have focused largely on early childhood [19, 20]. Adolescence, however, is a particularly important developmental period in individuals with ID due to the fact that there is variation across syndromes in terms of whether intellectual development is stable or slows during this period [21], which can have consequences for language development during this same period. Moreover, expressive language difficulties are known to be a significant predictor of adult independence given the influences of these skills on social success, adaptive functioning, and learning [8].

Existing longitudinal studies also have been limited by their reliance on standardized norm-referenced tests. Although standardized tests are useful to evaluate language performance relative to chronological age (CA) expectations, many of these tests (a) yield only a single or limited number of summary score(s) thereby obscuring potential differences across different areas of language; (b) show limited generalizability to everyday communicative contexts; and (c) are not specifically designed for individuals with ID and thus, often suffer from floor effects when used for this population [22]. As a result, standardized tests may mask variability across areas of expressive language for individuals with ID and mask differences between etiological groups [23].

The current study was designed to address these limitations. We used a longitudinal design to determine the commonalities and differences between individuals with DS and those with FXS in the emergence of their expressive language profiles during the adolescent period. We also controlled for differences in CA and nonverbal cognitive ability. Through the analysis of naturalistic language samples, we focused on characterizing the profiles of relative impairment across different functionally important areas of expressive language. We also examined factors that shape language development in individuals with ID due to DS or FXS. Elucidating the shared and syndrome-specific trajectories of growth across these areas underlying their development will contribute vital information for intervention planning for individuals with DS or FXS. Indeed, several clinical trials of targeted treatments in both individuals with DS and individuals with FXS have utilized gains in expressive language as the primary outcome measure for the treatment [18-21].

Expressive language development in individuals with DS All areas of expressive language development are significantly delayed relative to CA expectations in DS [24]. In 
addition, for individuals with DS, there is considerable research documenting that multiple areas of expressive language lag behind mental age (MA) expectations [15, $25,26]$. At the same time, severity of impairment varies across different areas of expressive language in DS. For example, individuals with DS score less well on measures of vocabulary and syntax when compared to both younger, typically developing (TD) peers [27-30] and similarly aged peers with other ID-related syndromes at similar cognitive level $[28,31-33]$. There is also evidence suggesting that expressive syntax skills are more impaired than are expressive vocabulary skills in individuals with DS [34]. In general, pragmatic language delays are often noted in individuals with DS, particularly relative to expectations based on nonverbal cognition [26, 3538]. That said, pragmatic strengths are often observed in DS, when compared to individuals with other neurodevelopmental disorders $[8,39,40]$. Sensory and motor impairments, as well as cognitive functioning (e.g., nonverbal MA), have been found to contribute to the expressive language problems of individuals with DS; however, these factors account for a relatively small proportion of the variance in expressive language outcomes [21, 23, 29-34, 36], suggesting a need for research to identify additional factors.

\section{Expressive language development in individuals with FXS}

In males with FXS, there are delays relative to CA expectations in multiple areas of expressive language [24]. However, the profile relative to MA expectations differs across areas of expressive language [41].

The syntactic complexity of expressive language is more limited in males with FXS than would be expected based on MA, and this finding is relatively consistent across multiple methods of assessment [28, 42-44]. Expressive pragmatics also appears to be an area of special weakness in FXS, including frequent off-topic and tangential utterances $[44,45]$, omission of critical story elements in narratives [42], and verbal perseveration (i.e., excessive repetition) of a word, phrase, or topic [46]. In contrast, expressive vocabulary keeps pace with MA expectations in males with FXS when assessed using standardized methods that require naming pictured objects [19]; however, delays relative to MA have been observed in the number of different words used by verbal individuals with FXS in naturalistic language samples [44, 47]. The expressive language profile associated with FXS appears to correlate with cognitive ability [47], behavior, and mental health symptoms (e.g., anxiety and hyperarousal; 48), and various symptoms of autism spectrum disorder (ASD), which are common among males with FXS [48, 49]. Again, however, the variance within and across areas of expressive language has yet to be explained in this population.

\section{Syndrome comparison studies of expressive language development}

Although both DS and FXS are each associated with expressive language difficulties, the severity and areas of relative strength and challenge appear to differ. There do not appear to be syndrome-related differences in vocabulary, at least as indexed by the number of different words produced [8]. Differences have emerged, however, in grammatical morphology and syntax. For example, Price and colleagues (2008) found that males with FXS produced more complex utterances overall and a longer mean length utterance (MLU) - a gross measure of syntactic complexity-in conversation than did MAmatched peers with DS. Similarly, individuals with FXS perform significantly better in terms of measures of expressive syntactic complexity in narration than do those with DS matched on cognitive level $[15,50]$. In terms of pragmatics, individuals with FXS produce more noncontingent discourse, stereotyped utterances, and perseverative language than do cognitively matched individuals with DS $[8,48]$. Finally, the occurrence of dysfluencies, including filled pauses and repetitions, which are thought to reflect problems with utterance planning, are more common in individuals with DS compared to those with FXS matched on cognitive level [16, 49].

The few longitudinal studies directly comparing the DS and FXS phenotypes have yielded contradictory findings. For example, a study by Roberts et al. [19] reported differences in the developmental trajectory of expressive vocabulary, using the Expressive Vocabulary Test-2 [51], between preschoolers with FXS or DS. In contrast, in a study by Martin et al. [28], no differences were observed in the rate of change in expressive vocabulary, using the Comprehensive Assessment of Spoken Language [52], between boys with DS and boys with FXS who were producing at least 40 words and producing utterances consisting of two or more words. Methodological differences across these studies, differences in participant CA, and the methods of assessment make it difficult to pinpoint why the findings relating to expressive vocabulary differed across these studies. Such findings highlight the need to use measures that have a wide age and ability range of use and to use multiple measures of the same constructs within a study to begin to understand task and context effects on expressive language.

In the present study, therefore, we used naturalistic procedures for obtaining conversational and narrative language samples that have been developed and standardized for use with verbal individuals with ID [16, 5355]. These expressive language sampling (ELS) measures have a wide age and ability level range of use, from the early school years through adulthood for TD individuals as well as for those with ID [56]. ELS conversational and narrative procedures pose somewhat different demands 
on speakers and thus, together provide a more comprehensive characterization of expressive language ability than is possible with any single measure. For example, speakers with FXS or DS both display significantly higher MLUs in narration than in conversation [14, 16, 57], suggesting that narration is particularly well-suited to eliciting the upper bounds of syntactic ability and uncovering individual differences [53]. Narrative may "pull" for syntactic complexity in part because it provides numerous opportunities (relative to conversation) to describe relationships between characters and event sequences, all of which are best achieved using multi-clause constructions [58]. In contrast, conversation may allow for more diverse vocabulary use because it is less constraining of the content of the talk [53]. Therefore, ELS procedures allow computation of several measures of expressive language with strong psychometric properties [59-61] and that have been shown to distinguish individuals with ID from TD individuals, individuals with ID at different levels of cognitive ability, and individuals with ID associated with different etiologies, including DS or FXS.

The specific ELS measures used provide indices of talkativeness, which reflects the social-motivational aspect of pragmatics; dysfluencies such as "um" and "er," which reflects problems in speech planning and execution; lexical diversity, which reflects functional vocabulary size; and mean length of utterance (MLU) in morphemes, which reflects syntax complexity. The utility of these particular measures in tracking developmental change and discriminating typically and atypically developing individuals has been established $[16,53,55$, 58]. Compared to other expressive language measures derived from the typical norm-referenced standardized tests, these expressive language measures are more likely to be generalizable to real-world activities meaningful for the individual with ID [62]. In addition, these measures all display minimal practice effects and have strong test-retest reliability for individuals with FXS and DS in the age range interest, which is important in longitudinal studies that, by definition, involved repeated administration of the same measures [56, 63]. Finally, intervention studies in individuals with different neurodevelopmental disorders have shown change in various ELS measures in the face of a lack of change in standardized tests [6466]. Thus, we used naturalistic conversation and narration language sampling techniques in a longitudinal design and computed these diverse measures of expressive language performance in verbal individuals with ID associated with DS and with FXS.

Sources of variation in expressive language development in individuals with DS or FXS

Not all individuals with ID or even a specific genetic disorder such as DS or FXS evidence precisely the same developmental trajectories or phenotypic outcomes. For example, a recent longitudinal study focused on vocabulary acquisition in preschoolers with DS showed that the lowest scoring child at 36 months was nonverbal (i.e., produced zero words), whereas the highest scoring child at the same age produced 243 words [67]. Moreover, when the children were re-assessed 6 months later in this same study, the nonverbal child remained nonverbal, whereas the one with the most developed language had doubled his word production. In a study of infant and toddler males with FXS [68], the lowest scoring child at 18 months was nonverbal, whereas the highest scoring child at the same age was producing ten words. After 6 months, the nonverbal child remained nonverbal, whereas the other child had tripled his production. Understanding the factors accounting for such variation, especially those factors that are modifiable, is critical for intervention efforts.

Identifying the sources of variation in phenotypic development requires a focus on factors at different levels of explanation-genetic, cellular, neural, cognitive, behavioral, and environmental [69]. In this respect, the language environment in which an individual develops can have strong influences on language development [70, 71]. In addition, higher levels of parental education are associated with better expressive language skills in TD children [72, 73], as well as in individuals with ID [6, 74-77]. Studies focused on individuals with FXS or DS have also suggested a positive association of maternal education with expressive vocabulary outcomes after controlling for CA [78]. Not all of these studies, however, have controlled for differences in the children's cognitive level, which makes it difficult to interpret their findings because variability in children's language development is likely to be related to cognitive differences [8]. In fact, neither Chapman et al. (2000) nor Estigarribia et al. (2012) found that maternal education predicted expressive syntax in DS after controlling for cognitive level and CA. The language environment, however, may have a variable impact on language development depending on the particular characteristics of the child, such as CA and level of intellectual functioning, as well the specific area of expressive language $[79,80]$.

Maternal cognitive ability could also impact language development. In the TD population, maternal IQ is related to child cognitive and language development [81, 82]. Although this association has often been attributed to genetics, it is very difficult to isolate the genetic from the environmental factors modulated by maternal IQ, as well as potential epigenetic effects [83], including in genetic syndromes associated with ID [84]. The link between maternal IQ and expressive language development has yet to be adequately investigated for ID; for example, there are reports of a link between maternal IQ and child IQ in FXS [76], but not in DS [85]. 
Maternal mental health has also been found to be associated with expressive language development in TD children [86] and in individuals with ID [75-77]. Depression, for example, can impede a person's ability to respond optimally in interactions with their children, which, in turn, can impede language development [87]. Maternal mental health is likely to be a source of withinand between-syndrome differences in DS and in FXS. In particular, the biological mothers of individuals with FXS are at elevated risk for mental health concerns (i.e., anxiety and depression-like symptoms) relative to mothers of children who have DS [88-90]. This is in part because of the former's own genetic status as carriers of either the FMR1 full mutation or premutation $[91,92]$. At the same time, parents of children with DS tend to report less child-related stress and are more optimistic about their children's potential outcomes than are parents of children with other IDs [89, 93], which may well shape interactions with their children.

At a more macro-level, there is evidence that socioeconomic circumstances influence language development. For a variety of reasons, children in lower income households tend to receive a significantly less rich language experience [94-96]. At the same time, socioeconomic factors are likely to interact with other dimensions of variability, such as the CA of the child $[97,98]$ and the child's phenotype [99-101]. In addition, it is important to note that when more expansive definitions of the verbal environment are applied, the link between socioeconomic environment and language development is not as clear [102].

In summary, multiple facets of the environment influence language development, but with different effects across different areas of language development. Few studies of DS or and FXS, however, have taken a multidimensional approach to investigating family-related influences of language development. Thus, in this study, we examined the relationship between different areas of expressive language development and different familyrelated factors. We focused on those factors known to be important for TD children and likely to be variable among families with ID: closeness in the mother-child relationship, maternal psychological distress, maternal level of education, maternal IQ, and family income. We were interested in whether and how these factors contributed to language development over and above the effects of diagnosis. These data will be valuable in guiding intervention efforts because although only few of the included family-related factors are to some degree modifiable (e.g., closeness in the mother-child relationship, maternal psychological distress) and thus, potential treatment targets, each of them still needs to be considered to address the special needs of a family (e.g., maternal and paternal level of education, family income).

\section{The current study}

The present study was designed to assess patterns and predictors of change in expressive language measures sampled annually in both conversation and narration across four time points during the transition from late childhood into adolescence in males with ID resulting from either DS or FXS. We took a multidimensional approach, selecting measures that index talkativeness, problems in language planning and execution, size of vocabulary, and syntactic complexity. In terms of predictors, we were especially interested in the roles of familyrelated factors, but we also considered level of nonverbal cognitive functioning and CA. The following research questions were addressed:

1. Does expressive language change over time in adolescent males with ID associated with FXS or DS? In addressing this question, we were interested in understanding which of the expressive language measures exhibited change over the four visits after accounting for differences in CA and nonlinguistic cognitive ability.

2. In those expressive language metrics that change, do diagnostic group (DS vs. FXS) and family-related factors predict change over time in adolescent males with ID? In addressing this question, we were interested in understanding (a) whether and how change in expressive language differed by diagnostic group after controlling for CA and nonlinguistic cognitive ability and (b) whether and how change in expressive language varied by family-related factors above and beyond CA, nonlinguistic cognitive ability, and diagnostic group.

In these analyses, therefore, we are moving beyond the obvious observation that language is impaired in individuals with ID to asking about the extent to which variations in language are attributable to etiology and/or to family-related factors.

\section{Method}

\section{Procedures}

Families were recruited for this research through newspaper advertisements, nationwide radio announcements, and a university registry of families with children who have developmental disabilities, as well as through postings on internet sites, listservs, and newsletters of developmental disability organizations. Prior to being enrolled in the study, parents of all participants signed informed consent forms approved by the associated Institutional Review Boards. Participants were administered annual assessments of nonverbal (NV) cognition, narrative language and conversational language, across 3 years for a total of up to four assessments. At the initial visit, 
mothers were administered an IQ assessment along with questionnaires focused on their mental health and the quality of the relationship with their children (described in "Family-related predictors" section). In general, the same examiner administered all assessments to any given participant at every annual assessment. Additionally, the scoring of all test protocols was checked by two examiners and all data entry was double-checked by two research assistants (further details are described in "Predictors" section).

The participants and measures reported on this project are a subset of those previously collected from a larger study (R01HD024356). Eligibility criteria for the larger study required participants to meet the following requirements based on parent report: (a) used speech as the primary mode of communication, (b) regularly used three-word or longer phrases, (c) were native English speakers, and (d) had no major uncorrected physical or sensory impairments that would interfere with performance in the study. Eligibility criteria also required hearing to be directly assessed into establish that pure tone thresholds no worse than $30 \mathrm{~dB}$ in the better ear. Several publications have emerged from the project (e.g., [8, 26, $59,103,104])$, and some have included the conversational and narrative language measures and participants included in the present study; however, no other reports have focused on the longitudinal data from the measures of language included in the present study or the full range of predictors of language examined here.

\section{Participants}

A total of 57 individuals with ID participated: 20 males with DS (CA at first visit: $M=12.8, S D=1.9$, range = 10.1-15.9 years) and 37 males with FXS (CA at first visit
$M=12.9, S D=1.7$, range $=10.2-16.0$ years), along with their biological mothers. See Table 1 for descriptive statistics on family-related measures and Table 2 for descriptive statistics on CA, NV cognition, and expressive language measures of participants at every time point.

\section{Measures \\ Dependent measures}

Expressive language Expressive language skills were assessed through both a conversation and a narration activity, each designed to elicit spontaneous language in meaningful social activities [53]. These activities were scripted to increase consistency in examiner behavior, content of talk, and nature of the interaction, thereby ensuring comparability of the language samples across participants and occasions of measurement $[22,56]$.

In conversation, each participant took part in an interview-style conversation with an examiner. The main goal of the examiner was to elicit as much talk from the participant as possible for $12 \mathrm{~min}$. The activity was introduced by saying that the examiner and participant would sit and talk for about $10 \mathrm{~min}$ to get to know each other a little better. Then the examiner moved to an idiosyncratic opening topic elicited from a previous interview with the caregiver (e.g., "I was talking to your mother and she told me that you love origami, that sounds very interesting to me. Tell me about that"). Then after, no more than $3 \mathrm{~min}$ on the idiosyncratic topic, the examiner moves to the first topic on a list (e.g., school day). The examiner attempts to use mainly open-ended prompts (e.g., "Tell me everything you did in school yesterday") and to limit her own speech. Reasonable standardization was ensured by use of a

Table 1 Characteristics of biological mothers and families of individuals with DS or FXS at baseline

\begin{tabular}{lll}
\hline Variables & Fragile X syndrome $(n=37)$ & Down syndrome $(n=20)$ \\
\hline Maternal education \% & & \\
- Graduated high school & 50.0 & 40.0 \\
- Graduated college & 30.6 & 55.0 \\
- Advanced degree & 19.4 & 5.0 \\
Paternal education, \% & & \\
- Graduated high school & 51.6 & 60.0 \\
- Graduated college & 25.8 & 30.0 \\
- Advanced degree & 22.6 & 10.0 \\
Family Income & $\$ 80,000(\$ 37,000)$ & $\$ 88,000(\$ 32,000)$ \\
Maternal current CA & $41.6(6.0)$ & $44.2(6.2)$ \\
Maternal IQ & $107.2(12.1)$ & $110.0(9.6)$ \\
Maternal GSI (SCL90-R) & $54.4(11.0)$ & $48.2(9.3)$ \\
Positive Affect Index & $25.0(3.5)$ & $25.3(2.3)$ \\
\hline
\end{tabular}

Living with both parents is missing for one FXS participant; maternal education is missing for one FXS participant, paternal education is missing for six FXS; Family Income is based on interval ratings as stated in the methods section. Family income is missing for one DS participant and two FXS participants; Maternal GSI missing for one DS participant and two FXS participants; Positive Affect Index is missing for one DS participant

IQ intellectual quotient, GSI general severity index, SCL90-R Symptom Checklist-90 Revised

Values represent means and standard deviations (in brackets) unless otherwise indicated. Variables followed with a \% represent percentages 
Table 2 Descriptive summaries by diagnosis and time points (DS vs. FXS)

\begin{tabular}{|c|c|c|c|c|c|c|c|c|}
\hline \multirow[t]{2}{*}{ Variables } & \multicolumn{4}{|c|}{ Fragile $X$ syndrome } & \multicolumn{4}{|l|}{ Down syndrome } \\
\hline & Baseline & Time 2 & Time 3 & Time 4 & Baseline & Time 2 & Time 3 & Time 4 \\
\hline Chronological age & $\begin{array}{l}\boldsymbol{n}=\mathbf{3 7} \\
12.9(1.7) \\
10.2-16\end{array}$ & $\begin{array}{l}\boldsymbol{n}=\mathbf{3 3} \\
13.7(1.7) \\
11.2-17\end{array}$ & $\begin{array}{l}\boldsymbol{n}=\mathbf{3 2} \\
14.9(1.8) \\
12.2-18\end{array}$ & $\begin{array}{l}\boldsymbol{n}=\mathbf{3 2} \\
15.8(1.7) \\
13.2-19\end{array}$ & $\begin{array}{l}\boldsymbol{n}=\mathbf{2 0} \\
12.8(1.9) 10.2-15.9\end{array}$ & $\begin{array}{l}\boldsymbol{n}=\mathbf{1 8} \\
13.9(2) \\
11.2-17\end{array}$ & $\begin{array}{l}\boldsymbol{n}=\mathbf{1 6} \\
14.8(2) \\
12.2-17.9\end{array}$ & $\begin{array}{l}\boldsymbol{n}=\mathbf{1 3} \\
15.4(1.9) \\
13.3-19\end{array}$ \\
\hline NV cognition (Leiter-R GS) & $\begin{array}{l}n=\mathbf{3 5} \\
466.3(9.4) \\
446-489\end{array}$ & $\begin{array}{l}n=\mathbf{3 0} \\
468.5(10) \\
440-489\end{array}$ & $\begin{array}{l}n=31 \\
468(9.5) \\
446-489\end{array}$ & $\begin{array}{l}\boldsymbol{n}=\mathbf{3 0} \\
468.5(10.2) \\
438-489\end{array}$ & $\begin{array}{l}n=19 \\
460.3(7.2) \\
442-474\end{array}$ & $\begin{array}{l}n=17 \\
463.3(8.4) \\
450-480\end{array}$ & $\begin{array}{l}n=15 \\
465.3(9.1) \\
449-483\end{array}$ & $\begin{array}{l}n=13 \\
469.5(9.8) \\
452-490\end{array}$ \\
\hline NV cognition (Leiter-R age equivalents) & $\begin{array}{l}n=36 \\
5.4(1.1) \\
3.3-8.3\end{array}$ & $\begin{array}{l}\boldsymbol{n}=\mathbf{3 3} \\
5.5(1.3) \\
2.8-9.5\end{array}$ & $\begin{array}{l}\boldsymbol{n}=32 \\
5.5(1.1) \\
3.4-8.2\end{array}$ & $\begin{array}{l}\boldsymbol{n}=\mathbf{3 2} \\
5.5(1.2) \\
2.9-8.6\end{array}$ & $\begin{array}{l}n=\mathbf{2 0} \\
4.7(0.7) \\
3.1-6.4\end{array}$ & $\begin{array}{l}\boldsymbol{n}=\mathbf{1 8} \\
4.9(1.1) \\
2.7-7.4\end{array}$ & $\begin{array}{l}\boldsymbol{n}=\mathbf{1 6} \\
5.2(1) \\
3.6-7.5\end{array}$ & $\begin{array}{l}n=13 \\
5.7(1.1) \\
3.8-8\end{array}$ \\
\hline Conversation & $n=33$ & $n=33$ & $n=28$ & $n=30$ & $n=17$ & $n=16$ & $n=11$ & $n=10$ \\
\hline Syntactic complexity & $\begin{array}{l}4.0(1.4) \\
1.9-7.0\end{array}$ & $\begin{array}{l}3.9(1.7) \\
1.3-8.4\end{array}$ & $\begin{array}{l}3.8(1.6) \\
1.2-7.2\end{array}$ & $\begin{array}{l}3.3(1.5) \\
1.2-7.4\end{array}$ & $\begin{array}{l}2.9(0.8) \\
1.8-4.3\end{array}$ & $\begin{array}{l}2.9(0.6) \\
2.0-4.1\end{array}$ & $\begin{array}{l}3.0(1.1) \\
1.4-5.1\end{array}$ & $\begin{array}{l}2.8(1.2) \\
1.6-5.5\end{array}$ \\
\hline Lexical diversity & $\begin{array}{l}86.9(28.2) \\
19-138\end{array}$ & $\begin{array}{l}83.8(33.0) \\
17-141\end{array}$ & $\begin{array}{l}82.5(31.4) \\
21-136\end{array}$ & $\begin{array}{l}73.7(30.9) \\
24-135\end{array}$ & $\begin{array}{l}64.9(15.8) \\
40-90\end{array}$ & $\begin{array}{l}65.6(17.5) \\
39-101\end{array}$ & $\begin{array}{l}65.4(23.3) \\
27-103\end{array}$ & $\begin{array}{l}63.3(16.9) \\
43-86\end{array}$ \\
\hline Talkativeness & $\begin{array}{l}12.7(3.5) \\
6.5-20.2\end{array}$ & $\begin{array}{l}12.9(4.1) \\
4.5-20.4\end{array}$ & $\begin{array}{l}14.8(3.4) \\
6.0-22.5\end{array}$ & $\begin{array}{l}15.1(5.0) \\
3.6-23.9\end{array}$ & $\begin{array}{l}12.9(3.6) \\
6.9-17.9\end{array}$ & $\begin{array}{l}12.8(4.3) \\
3.3-19.2\end{array}$ & $\begin{array}{l}11.4(3.1) \\
6.7-16.8\end{array}$ & $\begin{array}{l}11.8(4.1) \\
5.4-18.9\end{array}$ \\
\hline Dysfluency & $\begin{array}{l}0.2(0.1) \\
0-0.5\end{array}$ & $\begin{array}{l}0.2(0.1) \\
0-0.5\end{array}$ & $\begin{array}{l}0.1(0.1) \\
0.02-0.5\end{array}$ & $\begin{array}{l}0.2(0.1) \\
0.01-0.4\end{array}$ & $\begin{array}{l}0.2(0.2) \\
0.01-0.7\end{array}$ & $\begin{array}{l}0.3(0.2) \\
0.03-0.6\end{array}$ & $\begin{array}{l}0.2(0.1) \\
0.04-0.5\end{array}$ & $\begin{array}{l}0.2(0.2) \\
0.02-0.6\end{array}$ \\
\hline Narration: & $n=34$ & $n=31$ & $n=31$ & $n=29$ & $n=18$ & $n=15$ & $n=12$ & $n=10$ \\
\hline Syntactic complexity & $\begin{array}{l}4.7(1.7) \\
1-8\end{array}$ & $\begin{array}{l}4.7(1.7) \\
1.5-8.7\end{array}$ & $\begin{array}{l}4.3(1.8) \\
1.5-8.5\end{array}$ & $\begin{array}{l}4.4(1.7) \\
1.6-8.5\end{array}$ & $\begin{array}{l}3.5(1.4) \\
1.2-6\end{array}$ & $\begin{array}{l}3.7(1.2) \\
2-6.2\end{array}$ & $\begin{array}{l}4.6(1.5) \\
1.6-6.8\end{array}$ & $\begin{array}{l}4.1(2.2) \\
1.9-8.2\end{array}$ \\
\hline Lexical diversity & $\begin{array}{l}61.0(28.7) \\
1-128\end{array}$ & $\begin{array}{l}62.1(28.6) \\
11-123\end{array}$ & $\begin{array}{l}61.1(33.0) \\
15-122\end{array}$ & $\begin{array}{l}55.1(27.5) \\
9-108\end{array}$ & $\begin{array}{l}40.8(23.6) \\
5-79\end{array}$ & $\begin{array}{l}43.7(25.2) \\
2-83\end{array}$ & $\begin{array}{l}57.3(26.4) \\
24-103\end{array}$ & $\begin{array}{l}44.1(25.8) \\
15-87\end{array}$ \\
\hline Talkativeness & $\begin{array}{l}11.4(4.7) \\
0.3-22.1\end{array}$ & $\begin{array}{l}11.3(4.4) \\
4.1-17.4\end{array}$ & $\begin{array}{l}12.1(4.9) \\
4.1-22.5\end{array}$ & $\begin{array}{l}12.1(5.6) \\
3.9-29.9\end{array}$ & $\begin{array}{l}7.0(3.0) \\
3.2-14.1\end{array}$ & $\begin{array}{l}6.4(3.1) \\
0.3-12.2\end{array}$ & $\begin{array}{l}8.0(3.3) \\
3.5(13.1)\end{array}$ & $\begin{array}{l}5.9(1.7) \\
3.2-8.1\end{array}$ \\
\hline Dysfluency & $\begin{array}{l}0.2(0.1) \\
0-0.3\end{array}$ & $\begin{array}{l}0.1(0.1) \\
0-0.5\end{array}$ & $\begin{array}{l}0.1(0.1) \\
0-0.3\end{array}$ & $\begin{array}{l}0.1(0.1) \\
0-0.5\end{array}$ & $\begin{array}{l}0.3(0.2) \\
0-0.7\end{array}$ & $\begin{array}{l}0.3(0.2) \\
0.02-0.8\end{array}$ & $\begin{array}{l}0.2(0.2) \\
0.01-0.7\end{array}$ & $\begin{array}{l}0.3(0.2) \\
0.04-0.7\end{array}$ \\
\hline
\end{tabular}

Descriptive summaries of CA, NV cognition, and age equivalent (Leiter) and expressive language measures derived from conversation and narration (ELS) are represented by diagnosis and time point. Values represent sample size (bold/italic font), mean followed by standard deviation (in brackets) and range for each measure. Note that individuals may miss a visit, but return for a later visit; for example, in DS, 15 of 17 with conversation samples at time 1 were seen at time 3 or time 4 as were 14 of 18 with narration samples, so although sample sizes at the later time points are much lower than at time 1 , most individuals are still contributing to at least one of these later time points

CA chronological age, NV nonverbal, GS growth score

standard set of topics (e.g., school day, after-school, pets, companions, playing games, and vacations) and broad follow-up questions and prompts (e.g., "What do you like about [topic]? Tell me all about [topic]."). The examiner attempted to introduce at least three topics during the $12 \mathrm{~min}$. If a topic did not seem of interest to the participant, the examiner moved to the next topic trying at least one or two follow-up prompts for each topic. If a participant introduced topics not on the list, the examiner would keep that topic going by using appropriate follow-ups. If the examiner exhausted the predetermined topics but did not get $12 \mathrm{~min}$, up to two more idiosyncratic topics were introduced by the examiner. Two versions of the topic list were created. The versions were alternated across participants and time. Approximately half of the participants received version $A$ and half received version $B$. Topic order within each version was the same across participants.

In narration, participants were shown one of two wordless picture books, Frog Goes to Dinner or Frog on
His Own [105], counterbalanced across participants and time. The examiner introduced the book and showed each page for approximately $10 \mathrm{~s}$, allowing the participant to look through the entire story. The participant was then asked to tell the story to the examiner. This second time through the book, the experimenter controlled the turning of the pages turned a page 5 to $7 \mathrm{~s}$ after the participant had finished narrating to ensure that the participant had finished talking. Prompting was limited largely to the first page of the story, with the nature and timing of the prompts standardized.

Conversations and narrations were audio-recorded and later transcribed and analyzed using the Systematic Analysis of Language Transcripts (SALT [106];) software. The following dependent measures were derived from participant's language samples during conversation and during narration with the unit of analysis being the C-unit (i.e., an independent clause and its modifiers, which could include dependent clauses): (1) talkativeness (number of C-units attempted per minute), 
dysfluency (proportion of C-units that contained a verbal dysfluency, false start, or filler), (3) lexical diversity (number of different words in 50 complete and intelligible $\mathrm{C}$-units or the full sample if less than $50 \mathrm{C}$-units), and (4) syntactic complexity (mean length of utterance in morphemes, or MLU, for complete and intelligible Cunits). Each of the four dependent measures were included in our statistical models for conversation and for narration, with a total of eight dependent variables. Note that the first $10 \mathrm{~min}$ of conversation were transcribed as was the entire telling of the story on the second viewing of the book for narration. See Abbeduto et al. [16] for details of the transcription process. The scripted versions of conversation and narration described here yield highly reliable and valid estimates of talkativeness, dysfluency, lexical diversity, and MLU for individuals with ID of the ages studied and allow for discrimination of different etiological groups $[55,56,60,103]$. This is true even with samples per participant considerably less than the 100 utterances traditionally thought to be an adequate target for research [30, 44]. In fact, there is some evidence that even samples as brief as 3 min yield data sufficient for discriminating among groups of different language abilities [14, 16, 58].

We randomly selected for independent transcription $\sim 8 \%$ of the 358 samples collected to estimate intertranscriber agreement: 19 samples (ten narrations) from participants with DS and 22 samples (12 narrations) from participants with FXS. Dimensions of transcription relevant to the dependent measures of this study were assessed. For some metrics, agreement was a bit higher for FXS than for DS, perhaps reflecting the latter's poor intelligibility. Inter-transcriber agreement averaged $87 \%$ (DS) and 83\% (FXS) for segmentation into C-units, 89\% (DS) and 89\% (FXS) for identification of partly or fully unintelligible C-units, 99\% (DS) and 97\% (FXS) for identification of complete C-units, 93\% (DS) and 96\% (FXS) for identification of C-units containing mazes, 74\% (DS) and $79 \%$ for identification of the exact number of morphemes in each C-unit, 74\% (DS) and 83\% (FXS) for identification of the exact number of words in each Cunit, and $80 \%$ (DS) and $81 \%$ for the exact lexical and morphemic content of each C-unit. For the last three dimensions, we required that the two transcriptions were in complete agreement for a C-unit, which is a conservative approach to agreement [56].

\section{Predictors}

\section{Youth-related predictors}

Diagnostic group All participants were required to have been diagnosed with FXS or DS, with molecular confirmation based on DNA analysis for participants with FXS and chromosome analysis to document trisomy 21 or translocation for participants with DS. Diagnostic group (DS vs. FXS) was a predictor in the analyses.

Nonverbal cognition The Brief IQ subtests of the Leiter International Performance Scale-Revised (Leiter-R [107];) were administered. The Leiter is nonverbally administered (i.e., pantomimed) and no verbal responses are required. The subtests of the Brief IQ are: Figure Ground, Form Completion, Sequential Order, and Repeated Patterns, with the former two subtests focused on the visualization domain and the latter two on fluid reasoning. Growth scores (GSs) were used in our longitudinal analyses because they are equal-interval scores, also known as derived rasch scores, provide a measure of absolute ability, and demonstrated a normal distribution in our sample, unlike other type of scores (e.g., IQ scores showed floor effects, especially for the DS group, and age-equivalent scores which represent the median $\mathrm{CA}$ at which a raw score was obtained within the norming sample and are not on an equal interval scale $[23,108])$. Descriptive statistics regarding mental age equivalents of participants are also provided, however, at every time point for reference (see Table 2).

Initial chronological age Given that the chronological age (CA) of our participating youth at the first visit ranged from 10.1 to 16.0 years, CA at first visit was included as a potential predictor of change in expressive language variables over time.

\section{Family-related predictors}

Maternal IQ The Kaufman Brief Intelligence Test, Second Edition (KBIT-2 [109];) was administered on an individual basis to mothers. The KBIT-2 is a standardized measure consisting of two verbal subtests that require pointing to pictures representing words spoken by the examiner (Verbal Knowledge) or responding verbally to questions from the examiner (Riddles) and one NV subtest (Matrices) requiring completion of visually depicted puzzles by selecting the best option from among several. We used the composite standard score, which for the norming sample has a $M=100$ and $S D=15$.

Maternal psychological distress The Symptom Checklist-90 Revised (SCL90-R [110];) is a 90-item selfreport instrument that queries a range of mental health symptoms. Each symptom is rated from 0 (no distress) to 4 (extremely distressed). Scores for nine primary symptom dimensions are derived (e.g., obsessivecompulsive, depression, anxiety). We used the general severity index (GSI) T-scores $(M=50, S D=10$ for the norming sample) as our index of maternal psychological symptoms of distress. 
Closeness in the mother-child relationship The Positive Affect Index (PAI [111];) was used to assess the quality of the mother-child relationship. Five self-report items focused on the mother's perception of the youth's reciprocated closeness (i.e., how close she believed the youth felt toward her; Child-PAI: sum of items 1 to 5) were used from this 10-item self-report scale. Items rated understanding, trust, fairness, respect, and affection in the relationship on a 6-point scale. Possible scores for Child-PAI range from 5 to 30, with higher scores reflecting a higher quality of the relationship.

Maternal and paternal level of education Mothers were asked to indicate both their own level of education and that of their son's other parent, which in our sample was the father-if there was a second parent. Mothers selected the highest level of education achieved using categories ranging from 1 , complete elementary-middle school (K-8th) to 5, advanced degree.

Family income Mothers were asked to report family income by selecting a level from $<\$ 10,000$ to $>\$ 150,000$, with the levels defined in $\$ 10,000$ increments.

\section{Data Analysis}

Repeated measures, random effects models were used to assess patterns of change in each expressive language measure (talkativeness, dysfluency, lexical diversity, and syntax complexity) separately for conversation and narration, for a total of eight outcomes, across four annual time points. In those measures that changed over time, we further evaluated whether syndrome or familyrelated variables were associated with change over time for our sample of individuals with DS or FXS. To better meet the assumptions of the models, dysfluency in narration and conversation and syntax complexity in conversation were transformed with the natural logarithm prior to analysis.

Each analysis included the full sample of participants (participants with DS or FXS). To address the first aim of the study, we evaluated change over time for each dependent measure by including time in study (time in years since the baseline visit; 0 for baseline and 1, 2, or 3 for follow-up visits) as the primary independent variable; models further controlled for CA at baseline (centered at the mean age of 12.9 years), its interaction with study time, and Leiter-R GS at each visit as a time-varying covariate. To address the second aim of the study, we considered factors associated with change by adding a variable (such as diagnosis or a family-related variable) along with its interaction with time to the models for outcomes that exhibited change. We considered each family-related variable (KBIT-2 Composite IQ, PAI, GSI T-score (from SCL90-R), maternal and paternal levels of education, family income) in separate models due to the small sample size, but included diagnosis in each model to determine if the family-related factor was associated with change independent of diagnosis. In these models, the estimated coefficients ( $\beta \mathrm{s})$ for "time" and any interactions with "time" represent estimates of annual change and how other factors (such as syndrome) were associated with that change; coefficients for terms that do not include "time" reflected associations with the baseline level of an outcome (i.e., intercept). In particular, for non-transformed outcomes, the coefficients should be interpreted as the average difference in either the level or rate of change associated with a one-unit difference in the predictor. For the outcomes transformed using the natural $\log$, the exponentiated coefficient may be interpreted as the percentage difference in the level or rate of change associated with a one-unit difference in the predictor.

Random intercepts were included in all models to account for between-person variability in overall starting level. When supported by the data, random slopes were also included to account for between-person variability in change. Robust sandwich estimators were used for standard error estimation due to the small sample sizes. All analyses were conducted in SAS version 9.4, with a $p$ value less than 0.05 considered significant.

\section{Results \\ Descriptive statistics}

Table 1 provides a descriptive summary of the family characteristics for the participants at baseline. Consistent with previous findings in the literature [89], maternal psychological distress scores were lower for the DS group than for the FXS group, although the means for neither group was in the clinical range. The two groups were not significantly different on any of the other characteristics. Table 2 provides a descriptive summary of participants' CA, NV cognition, and expressive language sampling scores for each time point. Although there was a decrease in sample size for the later time-points in both groups, there were no significant differences in CA or expressive language sampling scores at baseline between those who dropped-out of the study early and those that remained in the study $(p>0.5$, except for dysfluency in conversation and syntax complexity and lexical diversity in narration for DS $(p>0.1)$ and talkativeness in conversation for FXS $(p=0.1))$.

Does expressive language (syntax complexity, lexical diversity, talkativeness, and dysfluency) in conversation and narration change over time in adolescent males with ID associated with DS or FXS?

In models that included baseline CA and nonverbal cognitive ability (as indexed by Leiter-R GS) at each visit, 
we estimated the annual rate of change across up to four visits for each expressive language measure in conversation and narration among our adolescent males with ID (Table 3). Only measures during conversation exhibited change in our sample (Fig. 1 and Table 3). Syntax complexity decreased by $6 \%$ per year, whereas lexical diversity decreased by 3.4 words per year. However, conversational talkativeness increased by 0.5 units per year (1.5 C-units higher per minute after 3 years).

\section{Do diagnostic group (DS vs FXS) and family-related factors predict change over time in expressive language in adolescent males with ID?}

After controlling for baseline CA and Leiter-R GS at each visit, diagnostic group (FXS vs. DS) accounted for differences only in the magnitude of change over time in conversational talkativeness (see Fig. 2 and Table 4). In particular, males with DS increased less over time in conversational talkativeness than did males with FXS ( $\beta$ $=-1.5, \mathrm{SE}=0.4, p<0.001,1.5$ fewer $\mathrm{C}$-units per minute per year). There were also differences at baseline between the diagnostic groups in these measures. On average, both syntax complexity and lexical diversity were lower in DS than in FXS; syntax complexity was $21 \%$ lower and lexical diversity was 15.9 words lower at baseline.

We further evaluated whether any of the baseline family-related variables predicted the rate of change in the conversational measures that exhibited change (see Fig. 3 and Table 5). No maternal or family-related variable predicted change over time in syntax complexity in conversation. However, PAI-child score was related to changes over time in lexical diversity in conversation, and maternal education predicted change over time in talkativeness in conversation. In particular, higher levels of the PAI-child variable predicted a lesser decrease in conversational lexical diversity. Finally, for talkativeness in conversation, those participants whose mothers had graduated college increased more over time than those whose mothers had only a high school education.

\section{Discussion}

This study was designed to identify areas of change in expressive language over time and predictors of change during adolescence in males with DS or FXS. Results from the present investigation suggest that adolescence is a significant period for expressive language development in youth with DS or FXS. In conversation, syntactic complexity, lexical diversity, and talkativeness changed over time. The fact that talkativeness increased with time for the full sample of participants (regardless of diagnostic group) suggested a growing ability or an increase in motivation to engage in linguistic interactions. However, no other increases were observed, and measures of lexical diversity and syntax complexity in conversation actually showed a decline over time for the full sample. It is unlikely, however, that this decline reflects a regression, or loss of lexical and syntactic skills. Instead, decreased lexical diversity and syntactic complexity may relate to task demands. In DS, there is evidence of early declines in concrete expressive language skills (i.e., semantic fluency) related to the early onset of Alzheimer's disease-related [112]; however, that decline is believed to begin several years post adolescence. Most importantly, no CA-related declines in lexical diversity or syntax complexity assessed in narration were observed for either diagnostic group, suggesting that something about the social or processing demands of conversation that are driving the decline. The declines in conversational performance seen may reflect a tradeoff between quantity and quality; that is, verbal individuals with ID, whether due to DS or FXS, may attempt to participate more fully in linguistic interaction as they grow older and normative expectations to talk increase, but they may be able to do so only by simplifying their contributions. Presumably, such simplifications are the cost of meeting the real-time dynamic requirements of increased participation in linguistic interaction.

We found minimal diagnostic group-related differences in expressive language in the rate of change over time. When adjusting for CA at baseline and level of NV cognitive ability at each visit as a time-varying covariate, diagnostic group-related differences were only observed in the rate of change in conversational talkativeness. Individuals with FXS showed larger increases in this variable compared to those with DS. We hypothesize that the superior lexical and syntactic skills of individuals with FXS at baseline may motivate, and make easier from a processing perspective, participation in conversation compared to individuals with DS. The latter's more

Table 3 Longitudinal change of ELS measures of participants with DS or FXS

\begin{tabular}{lllll}
\hline Context $[\beta(\mathrm{SE}), p]$ & Syntax complexity & Lexical diversity & Talkativeness & Dysfluency \\
\hline Conversation & $-\mathbf{0 . 0 6}(\mathbf{0 . 0 2}), \boldsymbol{p}=\mathbf{0 . 0 0 2}$ & $\mathbf{- 3 . 4}(\mathbf{1 . 4}), \boldsymbol{p}=\mathbf{0 . 0 2}$ & $\mathbf{0 . 5}(\mathbf{0 . 2}), \boldsymbol{p}=\mathbf{0 . 0 2}$ & $-0.007(0.02), p=0.7$ \\
Narration & $-0.07(0.08), p=0.4$ & $-1.7(1.2), p=0.2$ & $0.05(0.2), p=0.8$ & $-0.02(0.02), p=0.5$ \\
\hline
\end{tabular}

Dysfluency in narration and conversation and syntax complexity in conversation were transformed with the natural logarithm prior to analysis. The estimated coefficients ( $\beta$ s) represented estimates of annual change in a specific measure for the entire sample of participants (DS + FXS). Models included baseline CA, its interaction with time and time-varying Leiter-R GS. Bolded values have $p<0.05$

CA chronological age, GS growth score 

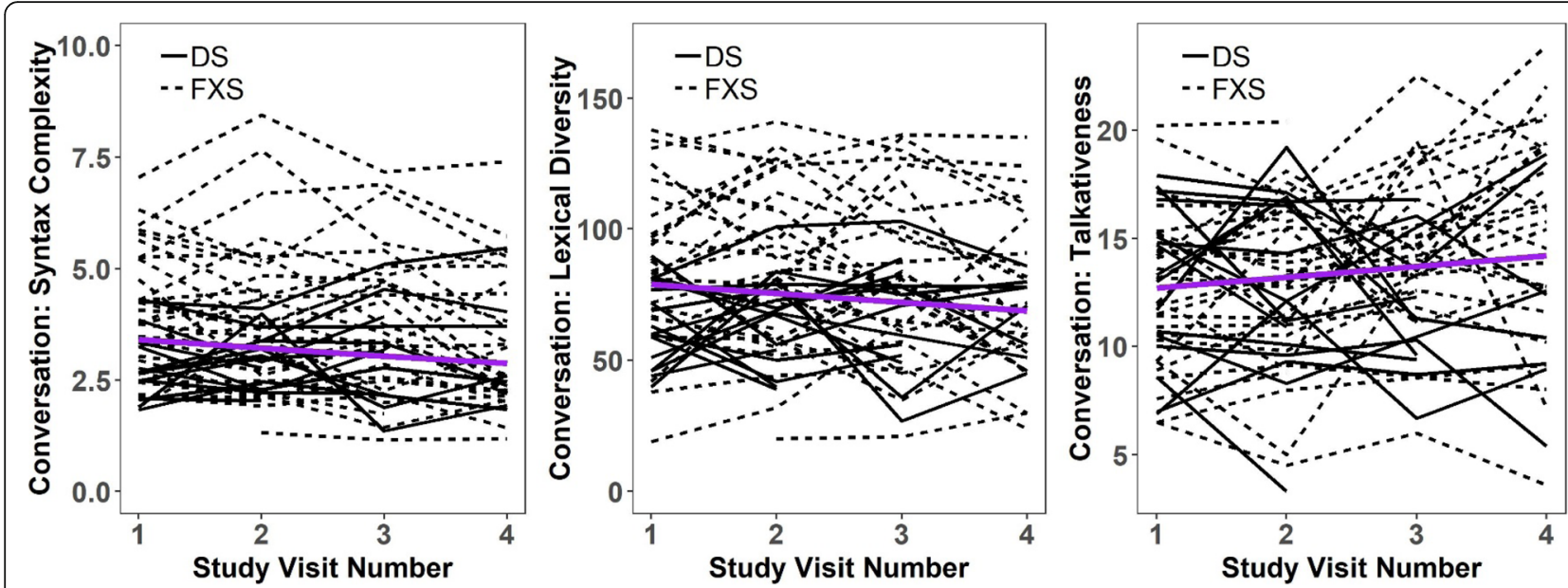

Fig. 1 Spaghetti plots representing syntax complexity, lexical diversity and talkativeness for the combined DS-FXS sample. Dashed lines represent participants with FXS; continuous lines represent participants with DS. The purple line represents estimated average trajectories over time for the combined sample (DS + FXS)

limited lexical and syntactic skills might lead to a reticence to participate. Further investigation, though, is needed to confirm this hypothesis.

Family-related factors also contributed to the rate of change with time in expressive language over and above the contributions of $\mathrm{CA}, \mathrm{NV}$ cognition, and diagnostic group. In particular, higher levels of maternal education were associated with a greater increase in talkativeness

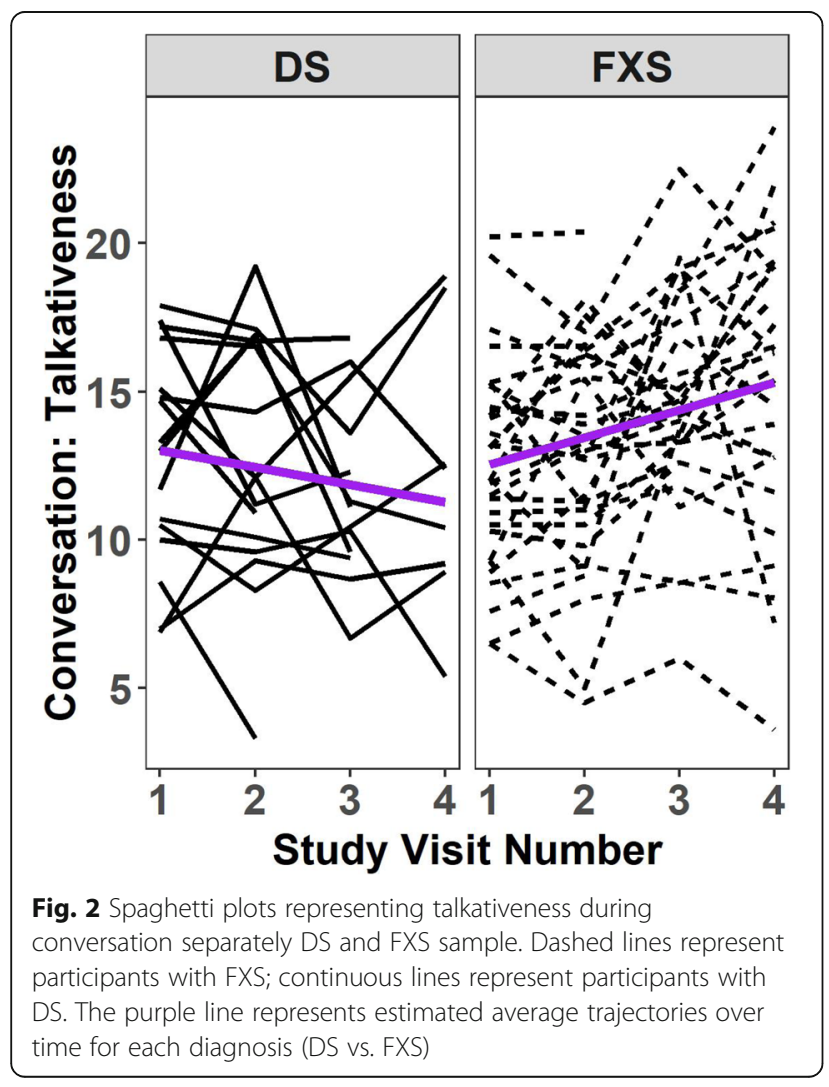

in conversation over time. Moreover, greater closeness in the mother-youth relationship predicted a lesser decline over time in lexical diversity in conversation. These factors are likely to be proxies for a constellation of more proximal variables, including the ways in which parents talk to, and interact with, their children. Understanding the pathways of influence of maternal education and perceived closeness will be important for designing individualized interventions that target parental behavior [77, 78, 113, 114]. At the same time, however, it is important to recognize the bidirectional and dynamic nature of the youth with DS or FXS and the environment provided by parents.

Although our focus in this study was understanding change over time in expressive language, we also found diagnosis-related differences at baseline (i.e., the first annual assessment). First, males with DS scored lower in lexical diversity in conversation at baseline than did males with FXS. This finding contrasts with previous studies that have failed to find differences in lexical diversity between verbal individuals with DS and those with FXS $[14,16]$. In part, this may reflect differences in the demands of the tasks used to assess expressive vocabulary. Even with expressive language sampling procedures, task differences have been found with conversation being found to elicit more diverse vocabulary than narration for a variety of typical and atypical populations [14]. Second, we found lower levels of syntax in expressive language samples of individual with DS than those with FXS. This finding is consistent with previous studies in demonstrating an especially severe delay in individuals with DS [12], with development lagging behind CA- and cognitive level-matched individuals with FXS $[15,16,20,30]$. Not all previous studies, however, have found these diagnosis-related differences in expressive 
Table 4 Association of diagnostic group with level and change of conversational ELS measures, while controlling for CA and nonverbal cognition

\begin{tabular}{llll}
\hline Variable $[\beta(\mathrm{SE}), p]$ & Syntax complexity & Lexical diversity & Talkativeness \\
\hline DS & $\mathbf{- 0 . 2 4}(\mathbf{0 . 0 8}), \boldsymbol{p}=\mathbf{0 . 0 0 3}$ & $-\mathbf{1 5 . 9}(\mathbf{5 . 3}), \boldsymbol{p}=\mathbf{0 . 0 0 4}$ & $0.49(0.99), p=0.6$ \\
Time & $-\mathbf{0 . 0 6}(\mathbf{0 . 0 2}), \boldsymbol{p}=\mathbf{0 . 0 0 3}$ & $-3.3(1.7), p=0.06$ & $\mathbf{0 . 9 2}(\mathbf{0 . 2 1}), \boldsymbol{p}<\mathbf{0 . 0 0 1}$ \\
DS $\times$ Time & $-0.02(0.03), p=0.6$ & $-0.42(2.18), p=0.8$ & $-\mathbf{1 . 5}(\mathbf{0 . 4}), \boldsymbol{p}<\mathbf{0 . 0 0 1}$
\end{tabular}

Syntax complexity was transformed with the natural logarithm prior to analysis. The coefficient for DS represents the average difference between DS and FXS at baseline in ELS. The coefficient for time is the estimated annual change in FXS and the coefficient for DS $\times$ time is the estimated difference in annual change between DS and FXS. Models include baseline CA, its interaction with time, and Leiter-R GS at each visit. Bolded values have $p<0.05$ DS Down syndrome, CA chronological age, GS growth score

syntax $[8,14,59,115]$. Also, in contrast to previous studies, the diagnosis-related differences in syntax were seen in conversation but not in narration in the present study. Conversation may place greater social demands on planning turns and with less visual support relative to narration, which may actually hinder syntactic performance more in verbal individuals with DS than in those with FXS.

\section{Limitations and future directions}

In closing, we acknowledge several limitations of this study. First, the sample size was relatively small; therefore, our conclusion should be taken cautiously. As a result, the small sample size required that we examine several predictors separately rather than together, which precluded determining their relative contributions to expressive language outcomes as well as any differences there might be in factors associated with expressive language in FXS and DS. Second, the SCL-90 is a measure of current maternal psychological distress, a variable that could change significantly over time. It also is possible that scores on the PAI could change over time, reflecting shifts in maternal perception of the mother-adolescent relationship. It would be interesting to track change in maternal stress and psychological state. Indeed, our original intent was to follow up with mothers at time 4 regarding these measures. However, we had a high number of mothers who chose not to participate in such assessment; therefore, we decided to only include baseline data in our analyses. Third, we examined only a few possible dimensions of the environment and we did not examine more proximal variables, such as the quality of parent-adolescent interactions. Research in this latter area would have direct implications for intervention. Fourth, females with FXS were excluded from our analyses, as well as females with DS in order to preserve sex-matching when comparing phenotypes. As in most previous studies, we excluded females with FXS because of the relatively lower severity of impairment compared to males. However, it is also true that many females with FXS display expressive language impairments [116] and thus, following them longitudinally would be important in future studies. Fifth, given the high number of individuals with FXS meeting criteria for an ASD diagnosis
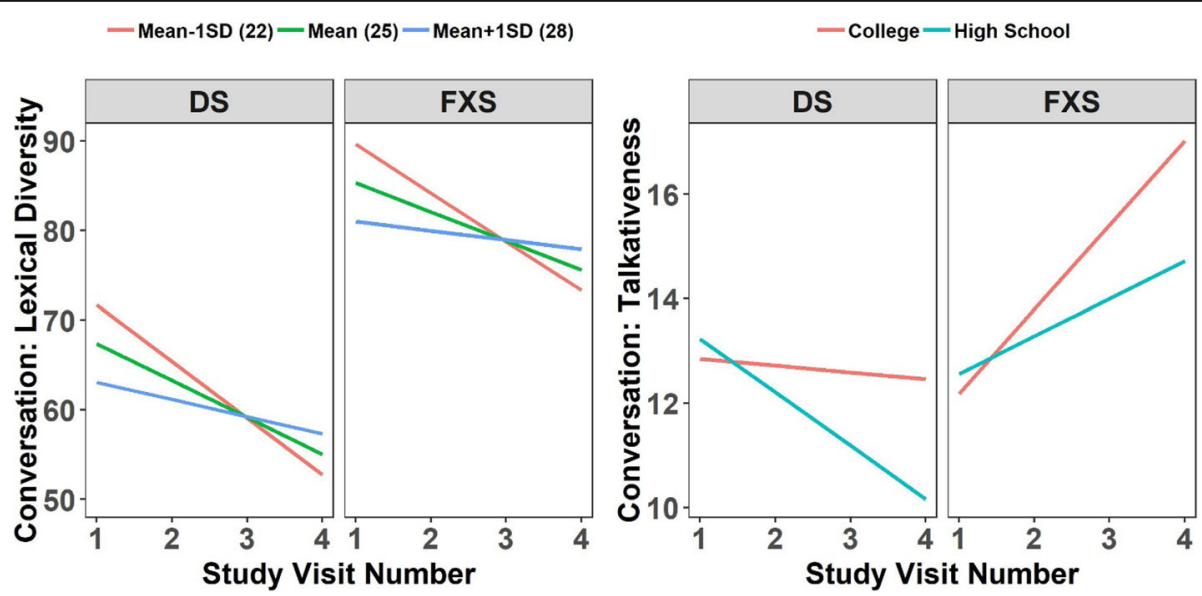

Fig. 3 Changes over time in lexical diversity and talkativeness during conversation predicted by family-related variables. Plot a represents estimated average trajectories over time in lexical diversity during conversation for individuals with maternal perception of child's reciprocated closeness at the mean (green), 1 standard deviation (SD) below the mean (red) and 1 SD above the mean (blue). Closer mother-child relationship was positively associated with the rate of change over time. Plot c represents estimated average trajectories over time in talkativeness during conversation for individuals with mothers who graduated college (red), and mothers who graduated high school (blue) 
Table 5 Association of family related variables with level and change of conversational ELS measures, while controlling for CA, diagnostic group (DS or FXS) and nonverbal cognition

\begin{tabular}{|c|c|c|c|}
\hline Variable $[\beta(S E), p]$ & Syntax complexity & Lexical diversity & Talkativeness \\
\hline \multicolumn{4}{|l|}{ Maternal education } \\
\hline High school & REF & REF & REF \\
\hline College & $0.1(0.1), p=0.3$ & $3.3(7.7), p=0.7$ & $-0.4(1.0), p=0.7$ \\
\hline Advanced degree & $0.004(0.2), p=0.9$ & $-1.2(10.2), p=0.9$ & $0.4(1.6), p=0.8$ \\
\hline \multicolumn{4}{|c|}{ Maternal education $\times$ time } \\
\hline High school & REF & REF & REF \\
\hline College & $0.002(0.03), p=0.9$ & $2.8(3.2), p=0.4$ & $0.9(0.3), p=0.009$ \\
\hline Advanced degree & $0.05(0.04), p=0.2$ & $4.6(2.9), p=0.1$ & $-0.4(0.5), p=0.4$ \\
\hline \multicolumn{4}{|l|}{ Paternal education } \\
\hline High school & REF & REF & REF \\
\hline College & $-0.2(0.2), p=0.3$ & $-10.9(10.7), p=0.3$ & $-0.4(1.1), p=0.7$ \\
\hline Advanced degree & $0.1(0.1), p=0.2$ & $6.7(8.2), p=0.4$ & $-2.9(1.2), p=0.02$ \\
\hline \multicolumn{4}{|c|}{ Paternal education $\times$ time } \\
\hline High school & REF & REF & REF \\
\hline College & $0.08(0.04), p=0.09$ & $7.6(3.6), p=0.04$ & $0.2(0.4), p=0.5$ \\
\hline Advanced degree & $0.003(0.04), p=0.9$ & $0.9(2.8), p=0.7$ & $0.3(0.5), p=0.5$ \\
\hline Maternal IQ & $0.004(0.004), p=0.3$ & $0.1(0.3), p=0.7$ & $0.05(0.04), p=0.2$ \\
\hline Maternal IQ $\times$ time & $0.0009(0.001), p=0.4$ & $0.1(0.1), p=0.2$ & $-0.01(0.02), p=0.4$ \\
\hline Maternal GSI & $-0.001(0.004), p=0.8$ & $0.2(0.3), p=0.6$ & $0.04(0.04), p=0.3$ \\
\hline Maternal GSI × time & $0.0004(0.001), p=0.8$ & $-0.1(0.1), p=0.3$ & $-0.0003(0.02), p=0.9$ \\
\hline Family income & $0.01(0.01), p=0.2$ & $0.8(0.8), p=0.3$ & $-0.1(0.1), p=0.5$ \\
\hline Family income $\times$ time & $0.003(0.004), p=0.5$ & $0.5(0.3), p=0.1$ & $-0.01(0.04), p=0.8$ \\
\hline PAl & $-0.02(0.01), p=0.2$ & $-1.4(1.1), p=0.2$ & $0.07(0.1), p=0.6$ \\
\hline PAI $\times$ time & $0.003(0.004), p=0.4$ & $0.7(0.3), p=0.03$ & $-0.02(0.04), p=0.7$ \\
\hline
\end{tabular}

Syntax complexity in conversation was transformed with the natural logarithm prior to analysis. Although paternal education has levels with a $p$ value $<0.05$, the overall assessment of paternal education with change in lexical diversity $(p=0.1)$ and with baseline level of talkativeness $(p=0.07)$ were not significant. Separate models were fit for each family-related variable. The terms with "Time" quantify the average difference in annual change associated with a 1-unit change (or relative to the reference group) in the predictor. Terms without "Time" correspond to associations with baseline levels ("intercept"). All models included baseline $C A$, diagnosis, their interactions with time, and time-varying Leiter-R GS $R E F$ reference group, $G S I$ general severity index, $P A /$ positive affect index

or displaying ASD-like symptoms [117], and previous literature on FXS showing an effect of autistic behaviors on communication development during childhood [118], ASD symptoms would have been an informative predictor, but were unavailable for participants with DS. Sixth, there was some missing data, although there were no significant differences between those with complete data and those with missing visits, keeping in mind that power to detect differences was limited by sample sizes. For all these reasons, larger studies will help to clarify our understanding of expressive language development and factors associated with it in DS and in FXS.

It is also important to note that given the nature of the current study, participants in the larger study from which data were taken were required to be verbal. This eligibility criteria fosters important bias into the sample, since there is a subgroup of adolescents with DS or FXS who are non- verbal and are not being represented in this study. Therefore, we acknowledge that this study does not address the full phenotypic spectrum for either disorder. Finally, our findings may not generalize to other age periods. For example, the observed changes with age aimed to vary with the nature of the disability might differ dramatically at a later age as a consequence of the high risk of developing the neuropathology associated with Alzheimer's disease and the resulting dementia-like symptoms for those with DS [119]. In summary, although the current study uses a multidimensional approach to examine patterns and predictors of change in expressive language during the transition from late childhood to adolescence in males with DS or FXS, further longitudinal investigations, including other potential predictors of interest (i.e., father-youth closeness, biomarkers of interest) with larger samples including females are needed to extend our results. 


\section{Conclusion}

Collectively, our results suggest that adolescence is an important period in expressive language development for youth with DS or FXS, during which they increase the number of attempts at communication, but also decrease the quality of their speech in terms of syntax and vocabulary in conversation. The inconsistency in terms of changes with age within and between diagnostic groups across contexts suggest that there is a need to assess structured expressive language under a broader range of speaking tasks and contexts, both from a research and a clinical perspective. In addition, our results reinforce the importance of considering the role of general NV cognition when it comes to understanding expressive language development of adolescents with DS or FXS. Finally, the observed associations between family-related factors and the trajectory of expressive language suggests that interventions aiming to improve expressive language development of individuals with DS or FXS should acknowledge or address the quality of the mother-youth relationship. Further research is needed to determine how best to capitalize on these results of this study in terms of developing treatments centered in the mother-youth relationship while considering the constellation of material, intellectual, and social resources and experiences of each family. Working on this relationship while considering independent resources, may provide added benefit to youth with DS or FXS receiving speech and language interventions.

\section{Abbreviations \\ ASD: Autism spectrum disorder; CA: Chronological age; DS: Down syndrome; FMR1: Fragile $X$ mental retardation 1 gene; FMRP: Fragile $X$ mental retardation 1 protein; FXS: Fragile X syndrome; GSI: General severity index; ID: Intellectual disability; IQ: Intellectual quotient; M: Mean; MA: Mental age; PAl: Positive Affect Index; SCL-90-R: The Symptom Checklist-90 Revised; \\ SD: Standard deviation; TD: Typically developing}

\section{Acknowledgements}

We thank the families who participated in this study and the many members of the laboratory who assisted with this project. This work was performed at the following sites: the MIND Institute (University of California Davis,

Sacramento, CA, USA), Waisman Center (University of Wisconsin-Madison, Madison, WI, USA) and New York State Institute for Basic Research in Developmental Disabilities (Staten Island, NY, USA).

\section{Authors' contributions}

LDH conceived the analytical plan for this study, interpreted the results, and wrote the manuscript. AJT was responsible for constructing and validating all data sets, verifying the written description of the methods, and assisting with interpretation of the statistical findings. DJH designed the analytical plan for this study and analyzed the data. STK contributed to the design and conduct of the larger study from which the data for this study were drawn and assisted with the interpretation of the findings of this study. LA conceived the overall design of the larger study and protocol from which the data for this study were drawn, oversaw data collection, contributed to the analytical plan for this study and the interpretation of the results. All authors reviewed, edited, and approved the manuscript.

\section{Funding}

This research was supported by grant R01HD024356 and by the MIND Institute Intellectual and Developmental Disabilities Research Center (U54
HD079125), both from the National Institute of Child Health and Human Development. The project described was also supported by the National Center for Advancing Translational Sciences (NCATS), National Institutes of Health (NIH), through grant UL1 TR000002.

\section{Availability of data and materials}

The datasets used and/or analyzed during the current study are available from the corresponding author on a reasonable request.

\section{Ethics approval and consent to participate}

The authors assert that all procedures contributing to this work comply with the ethical standards of the relevant national and institutional committees on human experimentation and with the Helsinki Declaration of 1975, as revised in 2008. Informed consent was obtained from the parent or guardian of each participant before testing.

\section{Consent for publication}

Not applicable.

\section{Competing interests}

The authors declare that they have no competing interests.

\section{Author details}

${ }^{1}$ The MIND Institute, University of California, Davis, 2825 50th Street, Rm 2101, Sacramento, CA 95817, USA. ²Department of Psychiatry and Behavioral Sciences, University of California, Davis, Sacramento, USA. ${ }^{3}$ Division of Biostatistics, Department of Public Health Sciences, University of California, Davis, Davis, CA, USA. ${ }^{4}$ Department of Speech and Hearing Sciences, University of Washington, Seattle, WA, USA.

Received: 11 July 2019 Accepted: 16 June 2020

Published online: 27 June 2020

\section{References}

1. World Health Organization (WHO). Genomic Resource Centre: Genes and human disease, genes and chromosomal diseases. World Health Organization; 2016 [cited 2016 Apr 11]. Available from: http://www.who.int/ genomics/public/geneticdiseases/en/index1.html.

2. Saldarriaga W, Tassone F, González-Teshima LY, Forero-Forero JV, AyalaZapata S, Hagerman R. Fragile X syndrome. Colomb médica (Cali, Colomb). 2014 [cited 2017 Apr 26];45(4):190-8. Available from: http://www. pubmedcentral.nih.gov/articlerender.fcgi?artid=4350386\&tool= pmcentrez\&rendertype=abstract

3. Hunter J, Rivero-Arias O, Angelov A, Kim E, Fotheringham I, Leal J. Epidemiology of fragile $X$ syndrome: a systematic review and meta-analysis. Am J Med Genet Part A. 2014[cited 2019 Jan 28];164(7):1648-58. Available from: http://www.ncbi.n/m.nih.gov/pubmed/24700618.

4. Ligsay A, Hagerman RJ. Review of targeted treatments in fragile $X$ syndrome. Intractable rare Dis Res. 2016 [cited 2017 Jan 24];5(3):158-67. Available from: http://www.ncbi.nlm.nih.gov/pubmed/27672538.

5. Erickson CA, Davenport MH, Schaefer TL, Wink LK, Pedapati E V, Sweeney $J A$, et al. Fragile $X$ targeted pharmacotherapy: lessons learned and future directions. J Neurodev Disord. 2017 [cited 2018 Jun 5];9:7. Available from: http://www.ncbi.n/m.nih.gov/pubmed/28616096.

6. Abbeduto L, McDuffie A, Thurman AJ, Kover ST. Language development in individuals with Intellectual and developmental disabilities. In: International Review of Research in Developmental Disabilities. Elsevier BV; 2016 [cited 2017 Jul 5]. p. 71-118. Available from: http://linkinghub.elsevier.com/ retrieve/pii/S2211609516300070.

7. Singer Harris NG, Bellugi U, Bates E, Jones W, Rossen M. Contrasting profiles of language development in children with williams and down syndromes. Dev Neuropsychol. 1997 [cited 2017 Jul 5];13(3):345-70. Available from: http://www.tandfonline.com/doi/abs/10.1080/87565649709540683.

8. del Hoyo Soriano L, Thurman AJ, Abbeduto L. Specificity: a phenotypic comparison of communication-relevant domains between youth with Down syndrome and fragile X syndrome. Front Genet. 2018 [cited 2018 Oct 1];9:424. Available from: https://www.frontiersin.org/article/10.3389/fgene.2 018.00424/full.

9. lacono T, Torr J, Wong HY. Relationships amongst age, language and related skills in adults with Down syndrome. Res Dev Disabil. 2010 [cited 
2017 May 12];31(2):568-76. Available from: http://www.ncbi.n/m.nih.gov/ pubmed/20045630.

10. Martin GE, Klusek J, Estigarribia B, Roberts JE. Language characteristics of individuals with Down syndrome. Top Lang Disord. 2009 [cited 2017 Mar 30];29(2):112-32. Available from: http://content.wkhealth.com/linkback/ openurl?sid=WKPTLP:landingpage\&an=00011363-200904000-00003.

11. Abbeduto L, Hagerman RJ. Language and communication in fragile $X$ syndrome. Ment Retard Dev Disabil Res Rev. 1997 [cited 2017 Jun 21];3(4): 313-22. Available from: http://doi.wiley.com/10.1002/\%28SICI\%291098-2 779\%281997\%293\%3A4\%3C313\%3A\%3AAID-MRDD6\%3E3.0.CO\%3B2-O.

12. Abbeduto L, Warren SF, Conners FA. Language development in Down syndrome: from the prelinguistic period to the acquisition of literacy. Ment Retard Dev Disabil Res Rev. 2007 [cited 2016 Apr 4];13(3):247-61. Available from: http://www.ncbi.n/m.nih.gov/pubmed/17910087.

13. Abbeduto L, Brady N, Kover ST. Language development and fragile $X$ syndrome: profiles, syndrome-specificity, and within-syndrome differences. Ment Retard Dev Disabil Res Rev.. 2007 [cited 2017 Sep 15];13(1):36-46. Available from: http://doi.wiley.com/10.1002/mrdd.20142.

14. Kover ST, Abbeduto L. Expressive language in male adolescents with fragile $X$ syndrome with and without comorbid autism. J Intellect Disabil Res. 2010 [cited 2017 Jun 2];54(3):246-65. Available from: http://doi.wiley.com/1 $0.1111 / j .1365-2788.2010 .01255 . x$

15. Finestack $L H$, Abbeduto $L$. Expressive language profiles of verbally expressive adolescents and young adults with Down syndrome or fragile $X$ syndrome. J Speech Lang Hear Res. 2010 [cited 2017 Jun 21];53(5):1334-48. Available from: http://www.ncbi.nlm.nih.gov/pubmed/20643789.

16. Kover ST, McDuffie A, Abbeduto L, Brown WT. Effects of sampling context on spontaneous expressive language in males with fragile $X$ syndrome or Down syndrome. J Speech Lang Hear Res. 2012 [cited 2018 Apr 26];55(4): 1022-38. Available from: http://www.ncbi.nlm.nih.gov/pubmed/22232386.

17. McDuffie A, Banasik A, Bullard L, Nelson S, Feigles RT, Hagerman R, et al. Distance delivery of a spoken language intervention for school-aged and adolescent boys with fragile X syndrome. Dev Neurorehabil. 2018 [cited 2018 Jun 7];21(1):48-63. Available from: http://www.ncbi.nlm.nih.gov/ pubmed/28956679.

18. Finestack L, O'Brien KH, Hyppa-Martin J, Lyrek KA. The evaluation of a personal narrative language intervention for school-age children with down syndrome. In: American Journal on Intellectual and Developmental Disabilities. American Association on Mental Retardation; 2017 [cited 2020 Mar 30]. p. 310-32. Available from: http://www.ncbi.nlm.nih.gov/pubmed/2 8654416.

19. Roberts JE, Price J, Barnes E, Nelson L, Burchinal M, Hennon EA, et al. Receptive vocabulary, expressive vocabulary, and speech production of boys with fragile $X$ syndrome in comparison to boys with down syndrome. Am J Ment Retard. 2007 [cited 2017 Aug 23];112(3):177. Available from: http://www.aaiddjournals.org/doi/abs/10.1352/0895-8017(2007)112[177: RVEVAS]2.0.CO;2.

20. Price J, Roberts J, Vandergrift N, Martin G. Language comprehension in boys with fragile $X$ syndrome and boys with Down syndrome. J Intellect Disabil Res. 2007 [cited 2017 Jun 21];51(Pt 4):318-26. Available from: http://doi. wiley.com/10.1111/j.1365-2788.2006.00881.x.

21. Kover ST, Pierpont El, Kim J-S, Brown WT, Abbeduto L. A neurodevelopmental perspective on the acquisition of nonverbal cognitive skills in adolescents with fragile X syndrome. Dev Neuropsychol. 2013;38(7): 445-60 Available from: http://www.ncbi.nlm.nih.gov/pubmed/24138215.

22. Abbeduto L, Kover ST, McDuffie A. Studying the language development of children with INTELLECTUAL disabilities. In: Research Methods in Child Language. Oxford: Wiley-Blackwell; 2012 [cited 2018 Jun 7]. p. 330-46. Available from: http://doi.wiley.com/10.1002/9781444344035.ch22.

23. Mervis CB, Robinson BF. Designing measures for profiling and genotype/ phenotype studies of individuals with genetic syndromes or developmental language disorders. Appl Psycholinguist. 2005 [cited 2019 Jul 8];26(1):41-64. Available from: https://www.cambridge.org/core/product/identifier/S0142 716405050058/type/journal_article.

24. Abbeduto L, Warren SF, Conners FA. Language development in Down syndrome: from the prelinguistic period to the acquisition of literacy. Mrdd Res Rev. 2007 [cited 2018 May 7];13:247-61. Available from: https:// onlinelibrary.wiley.com/doi/pdf/10.1002/mrdd.20158.

25. Lee M, Bush L, Martin GE, Barstein J, Maltman N, Klusek J, et al. A multimethod investigation of pragmatic development in individuals with Down syndrome. Am J Intellect Dev Disabil. 2017 [cited 2017 Jun 28];122(4):289-
309. Available from: http://www.aaiddjournals.org/doi/10.1352/1944-755 8-122.4.289.

26. Channell MM, McDuffie AS, Bullard LM, Abbeduto L. Narrative language competence in children and adolescents with Down syndrome. Front Behav Neurosci. 2015 [cited 2016 May 9];9:283. Available from: http://www. pubmedcentral.nih.gov/articlerender.fcgi?artid=4626566\&tool= pmcentrez\&rendertype=abstract.

27. Chapman RS, Hesketh LJ, Kistler DJ. Predicting longitudinal change in language production and comprehension in individuals with Down syndrome: hierarchical linear modeling. J Speech Lang Hear Res. 2002 [cited 2017 May 12];45(5):902-15. Available from: http://www.ncbi.nlm.nih.gov/ pubmed/12381048.

28. Martin GE, Losh M, Estigarribia B, Sideris J, Roberts J. Longitudinal profiles of expressive vocabulary, syntax and pragmatic language in boys with fragile $X$ syndrome or Down syndrome. Int J Lang Commun Disord. 2013 [cited 2017 Jun 13];48(4):432-43. Available from: http://www.ncbi.nlm.nih.gov/ pubmed/23889838.

29. Næss K-AB, Lyster S-AH, Hulme C, Melby-Lervåg M. Language and verbal short-term memory skills in children with Down syndrome: a meta-analytic review. Res Dev Disabil. 2011;32(6):2225-34.

30. Price JR, Roberts JE, Hennon EA, Berni MC, Anderson KL, Sideris J. Syntactic complexity during conversation of boys with fragile $X$ syndrome and Down syndrome. J Speech Lang Hear Res. 2008 [cited 2017 Jul 31];51(1):3. Available from: http://www.ncbi.nlm.nih.gov/pubmed/18230852.

31. Abbeduto L, Pavetto $M$, Kesin E, Weissman M, Karadottir $S, O$ 'Brien A, et al. The linguistic and cognitive profile of Down syndrome: Evidence from a comparison with fragile X syndrome. Down Syndr Res Pract. 2001 [cited 2017 Sep 15];7(1):9-15. Available from: http://www.down-syndrome.org/ reports/109/.

32. Eadie PA, Fey ME, Douglas JM, Parsons CL. Profiles of grammatical morphology and sentence imitation in children with specific language impairment and Down syndrome. J Speech Lang Hear Res. 2002 [cited 2016 May 9];45(4):720-32. Available from: http://www.ncbi.nlm.nih.gov/ pubmed/12199402.

33. Thordardottir ET, Chapman RS, Wagner L. Complex sentence production by adolescents with Down syndrome. Appl Psycholinguist. 2002 [cited 2017 May 10];23:163-83. Available from: https://www.cambridge.org/core/ services/aop-cambridge-core/content/view/S0142716402002011.

34. Laws G, Bishop D.V.M. A comparison of language abilities in adolescents with Down syndrome and children with specific language impairment. J Speech Lang Hear Res. 2003 [cited 2019 Oct 29];46(6):1324-39. Available from: http://www.ncbi.nlm.nih.gov/pubmed/14700358.

35. Abbeduto L, Murphy MM, Richmond EK, Amman A, Beth P, Weissman MD, et al. Collaboration in referential communication: comparison of youth with Down syndrome or fragile X syndrome. Am J Ment Retard. 2006 [cited 2017 Jul 6];111(3):170. Available from: http://www.aaiddjournals.org/doi/abs/1 0.1352/0895-8017(2006)111[170:CIRCCO]2.0.CO;2

36. Abbeduto L, Murphy MM, Kover ST, Giles ND, Karadottir S, Amman A, et al. Signaling noncomprehension of lanquage: a comparison of fragile $X$ syndrome and Down syndrome. Am J Ment Retard. 2008 [cited 2018 Jun 14];113(3):214-30. Available from: http://www.ncbi.nlm.nih.gov/pubmed/184 07723.

37. Ashby SA, Channell MM, Abbeduto L. Inferential language use by youth with Down syndrome during narration. Res Dev Disabil. 2017 [cited 2017 Oct 16];71:98-108. Available from: http://linkinghub.elsevier.com/retrieve/pii/ S0891422217302470.

38. Lee M, Bush L, Martin GE, Barstein J, Maltman N, Klusek J, et al. A multimethod investigation of pragmatic development in individuals with Down syndrome. Am J Intellect Dev Disabil. 2017 [cited 2019 Apr 29];122(4):289309. Available from: http://www.aaiddjournals.org/doi/10.1352/1944-755 8-122.4.289.

39. Barstein J, Martin GE, Lee M, Losh M. A Duck Wearing Boots?! Pragmatic language strategies for repairing communication breakdowns across genetically based neurodevelopmental disabilities. J Speech Lang Hear Res. 2018 [cited 2018 Jun 28];61(6):1440. Available from: http://js/hr.pubs.asha. org/article.aspx?doi=10.1044/2018_JSLHR-L-17-0064.

40. Thurman AJ, Fisher MH. The Williams syndrome social phenotype: disentangling the contributions of social interest and social difficulties. Int Rev Res Dev Disabil. 2015.

41. Reiss AL, Hall SS. Fragile X Syndrome: assessment and treatment implications. Child Adolesc Psychiatr Clin N Am. 2007 [cited 2018 May 29]; 
16(3):663-75. Available from: https:/www.sciencedirect.com/science/article/ pii/S1056499307000296?via\%3Dihub.

42. Estigarribia B, Roberts JE, Sideris J, Price J. Expressive morphosyntax in boys with Fragile $X$ syndrome with and without autism spectrum disorder. Int J Lang Commun Disord. 2011 [cited 2017 Jun 16];46(2):216-30. Available from: http://www.ncbi.nlm.nih.gov/pubmed/21401819.

43. Komesidou R, Brady NC, Fleming K, Esplund A, Warren SF. Growth of expressive syntax in children with fragile $X$ syndrome. J Speech Lang Hear Res. 2017 [cited 2018 Jul 5];60(2):422-34. Available from: http://www.ncbi. nlm.nih.gov/pubmed/28219082.

44. Roberts JE, Hennon EA, Price JR, Dear E, Anderson K, Vandergrift NA. Expressive language during conversational speech in boys with fragile $X$ syndrome. Am J Ment Retard. 2007 [cited 2017 Aug 23];112(1):1. Available from: http://www.aaiddjournals.org/doi/abs/10.1352/0895-8017(2007)112[1: ELDCSI]2.0.CO;2.

45. Sudhalter V, Cohen IL, Silverman W, Wolf-Schein EG. Conversational analyses of males with fragile $X$, Down syndrome, and autism: comparison of the emergence of deviant language. Am J Ment Retard. 1990 [cited 2017 Jul 6]; 94(4):431-41. Available from: http://www.ncbi.nlm.nih.gov/pubmed/213 7003.

46. Belser RC, Sudhalter V. Conversational characteristics of children with fragile X syndrome: repetitive speech. Am J Ment Retard. 2001 [cited 2017 Jul 6]; 106(1):28. Available from: http://www.ncbi.nlm.nih.gov/pubmed/11246710.

47. Sudhalter V, Belser RC. Conversational characteristics of children with fragile X syndrome: tangential language. Am J Ment Retard. 2001 [cited 2017 Jun 21];106(5):389-400. Available from: http://www.aaiddjournals.org/doi/abs/1 0.1352/0895-8017(2001)106\%3C0389:CCOCWF\%3E2.0.CO;2.

48. Roberts J, Martin GE, Moskowitz L, Harris AA, Foreman J, Nelson L. Discourse skills of boys with fragile $X$ Syndrome in comparison to boys with Down syndrome. J Speech Lang Hear Res. 2007. Available from: https://pubmed. ncbi.nlm.nih.gov/17463242/.

49. Van Borsel J, Tetnowski JA. Fluency disorders in genetic syndromes. J Fluen Disord. 2007 [cited 2018 Jul 24];32(4):279-96. Available from: https://www. sciencedirect.com/science/article/pii/S0094730X07000411?via\%3Dihub.

50. Keller-Bell YD, Abbeduto L. Narrative development in adolescents and young adults with fragile $x$ syndrome. Am J Ment Retard. 2007 [cited 2017 May 12];1 12(4):289-99. Available from: http://www.aaiddjournals.org/doi/ abs/10.1352/0895-8017(2007)112[289:NDIAAY]2.0.CO;2.

51. Williams KT. Expressive Vocabulary Test (EVT-2). Circle Pines: American Service; 1997

52. Carrow-Woolfolk E. Comprehensive assessment of spoken language. Circle Pines: American Guidance Service; 1999

53. Abbeduto L, Benson G, Short K, Dolish J. Effects of sampling context on the expressive language of children and adolescents with mental retardation. Ment Retard. 1995 [cited 2017 Jul 6];33(5):279-88. Available from: http:// www.ncbi.nlm.nih.gov/pubmed/7476250.

54. Berry-Kravis E, Doll E, Sterling A, Kover ST, Schroeder SM, Mathur S, et al. Development of an expressive language sampling procedure in fragile $X$ syndrome. J Dev Behav Pediatr. 2013 [cited 2017 Mar 21];34(4):245-51. Available from: http://www.ncbi.nlm.nih.gov/pubmed/23669871.

55. Channell MM, Loveall SJ, Conners FA, Harvey DJ, Abbeduto L. Narrative language sampling in typical development: implications for clinical trials. Am J Speech-Language Pathol. 2018 [cited 2018 Apr 26];27(1):123. Available from: http://ajslp.pubs.asha.org/article.aspx?doi=10.1044/2017_AJSLP-17-0046.

56. Abbeduto L, Berny-Kravis E, Sterling A, Sherman S, Edgin JO, McDuffie A, et al. Expressive language sampling as a source of outcome measures for treatment studies in fragile $X$ syndrome: Feasibility, practice effects, test-retest reliability, and construct validity. J Neurodev Disord. 2020 [cited 2020 Mar 30];12(1):10. Available from: http://www.ncbi.n/m.nih.gov/pubmed/32204695.

57. Miles S, Chapman R, Sindberg H. Sampling Context Affects MLU in the Language of adolescents with Down syndrome. I Speech Lang Hear Res. 2006 [cited 2018 Aug 30];49(2):325. Available from: http://jslhr.pubs.asha.org/ article.aspx?doi=10.1044/1092-4388(2006/026).

58. Heilmann J, Nockerts A, Miller JF. Language sampling: does the length of the transcript matter? Lang Speech Hear Serv Sch. 2010 [cited 2019 Jul 8];41(4): 393-404. Available from: http:/www.ncbi.nlm.nih.gov/pubmed/20601531.

59. Finestack LH, Sterling AM, Abbeduto L. Discriminating Down syndrome and fragile X syndrome based on lanquage ability. J Child Lang. 2013 [cited 2017 May 19];40(1):244-65. Available from: http://www.ncbi.nlm.nih.gov/ pubmed/23217297.
60. Berry-Kravis E, Doll E, Sterling A, Kover ST, Schroeder SM, Mathur S, et al. Development of an expressive language sampling procedure in fragile $X$ syndrome: a pilot study. J Dev Behav Pediatr. 2013 [cited 2018 Apr 26];34(4): 245-51. Available from: http://www.ncbi.nlm.nih.gov/pubmed/23669871.

61. Shaffer RC, Schmitt L, John Thurman A, Abbeduto L, Hong M, Pedapati E, et al. The relationship between expressive language sampling and clinical measures in fragile X syndrome and typical development. Brain Sci. 2020 [cited 2020 Feb 25];10(2):66. Available from: http://www.ncbi.nlm.nih.gov/ pubmed/31991905.

62. Westerveld MF, Gillon GT, Miller JF. Spoken language samples of New Zealand children in conversation and narration. Adv Speech Lang Pathol. 2004 [cited 2018 Jun 7];6(4):195-208. Available from: http://www. tandfonline.com/doi/full/10.1080/14417040400010140.

63. Abbeduto L, Thurman AJ, Sterling A, Edgin JO, Sherman S, Berry-Kravis E. Measuring spoken language to evaluate treatment efficacy for Down syndrome. Presentation at the Biennial Conference of the Trisomy 21 Research Society, Ba; 2019.

64. Kaiser AP, Roberts MY. Parent-implemented enhanced milieu teaching with preschool children who have intellectual disabilities. J Speech, Lang Hear Res. 2013 [cited 2020 Feb 25];56(1):295-309. Available from: http://www. ncbi.nlm.nih.gov/pubmed/22744141.

65. Casenhiser DM, Binns A, McGill F, Morderer O, Shanker SG. Measuring and supporting language function for children with autism: evidence from a randomized control trial of a social-interaction-based therapy. J Autism Dev Disord. 2015 [cited 2020 Feb 25];45(3):846-57. Available from: http://www. ncbi.nlm.nih.gov/pubmed/25234481.

66. Thurman AJ, Potter LA, Kim K, Tassone F, Banasik A, Nelson S et al. Controlled trial of lovastatin combined with an open label treatment of a parent- implemented language intervention in youth with fragile $X$ syndrome. 2020;

67. Zampini L, D'Odorico L. Communicative gestures and vocabulary development in 36-month-old children with Down's syndrome. Int J Lang Commun Disord. 2009 [cited 2017 Mar 30];44(6):1063-73. Available from: http://doi.wiley.com/10.1080/13682820802398288.

68. Kover ST, McCary LM, Ingram AM, Hatton DD, Roberts JE. Language development in infants and toddlers with fragile $\mathrm{X}$ syndrome: change over time and the role of attention. Am J Intellect Dev Disabil. 2015 [cited 2018 Jun 5];120(2):125-44. Available from: http://www.ncbi.nlm.nih.gov/ pubmed/25715182.

69. Karmiloff-Smith A, Al-Janabi T, D'Souza H, Groet J, Massand E, Mok K, et al. The importance of understanding individual differences in Down syndrome. F1000Research. 2016 [cited 2018 Feb 20];5. Available from: http://www.ncbi. nlm.nih.gov/pubmed/27019699.

70. Levickis P, Reilly S, Girolametto L, Ukoumunne OC, Wake M. Associations between maternal responsive linguistic input and child language performance at age 4 in a community-based sample of slow-to-talk toddlers. Child Care Health Dev. 2018 [cited 2019 Jan 30];44(5):776-83. Available from: http://www.ncbi.nlm.nih.gov/pubmed/30043426.

71. Brady N, Warren SF, Sterling A. Interventions aimed at improving child language by improving maternal responsivity. Int Rev Res Ment Retard. 2009 [cited 2017 Mar 30];37:333-57. Available from: http://www.ncbi.nlm. nih.gov/pubmed/21326620.

72. Hoff E, Burridge A, Ribot KM, Giguere D. Language specificity in the relation of maternal education to bilingual children's vocabulary growth. Dev Psychol. 2018 [cited 2019 Jan 30];54(6):1011-9. Available from: http://www. ncbi.nlm.nih.gov/pubmed/29283595.

73. Richels CG, Johnson KN, Walden TA, Conture EG. Socioeconomic status, parental education, vocabulary and language skills of children who stutter. J Commun Disord . 2013 [cited 2019 Feb 1];46(4):361-74. Available from: http://www.ncbi.nlm.nih.gov/pubmed/23906898.

74. Brady N, Warren SF, Fleming K, Keller J, Sterling A. Effect of sustained maternal responsivity on later vocabulary development in children with Fragile X syndrome. J Speech Lang Hear Res. 2014 [cited 2017 Jul 24];57(1): 212. Available from: http://www.ncbi.nlm.nih.gov/pubmed/24023370.

75. del Hoyo Soriano L, Thurman AJ, Harvey DJ, Ted Brown W, Abbeduto L. Genetic and maternal predictors of cognitive and behavioral trajectories in females with fragile X syndrome. J Neurodev Disord. 2018 [cited 2018 Jun 21];10(1):22. Available from: https://jneurodevdisorders.biomedcentral.com/ articles/10.1186/s11689-018-9240-2.

76. Dyer-friedman J, Glaser B, Hessl D, Johnston C, Huffman LC, Taylor A, et al. Genetic and environmental influences on the cognitive outcomes of 
children with fragile X syndrome. J Am Acad Child Adolesc Psychiatry. 2002 [cited 2017 Jul 10];41:237-44. Available from: http://ac.els-cdn.com/ S0890856709607802/1-s2.0-S0890856709607802-main.pdf?_tid=025ab756-65 a6-11e7-ac3a-00000aacb35d\&acdnat=1499715113_6bcc0882d41078403c3 0b234faee7c7d.

77. Warren SF, Brady N, Sterling A, Fleming K, Marquis J. Maternal responsivity predicts language development in young children with fragile $X$ syndrome. Am J Intellect Dev Disabil. 2010 [cited 2018 Feb 16];115(1):54-75. Available from: http://www.ncbi.nlm.nih.gov/pubmed/20025359.

78. Deckers SRJ., Van Zaalen Y, Van Balkom H, Verhoeven L. Predictors of receptive and expressive vocabulary development in children with Down syndrome. Int J Speech Lang Pathol. 2017 [cited 2018 May 14];1-13. Available from: https://www.tandfonline.com/doi/full/10.1080/17549507.201 7.1363290 .

79. Sterling A, Warren SF. Maternal responsivity in mothers of young children with Down syndrome. Dev Neurorehabil. 2014 [cited 2019 Jan 31];17(5): 306-17. Available from: http://www.ncbi.nlm.nih.gov/pubmed/23869952.

80. Sterling A, Warren SF. Parenting of children with Down syndrome compared to fragile X syndrome. Dev Neurorehabil. 2018 [cited 2018 Jun 25];21(1):64-7. Available from: https://www.tandfonline.com/doi/full/10.1 080/17518423.2016.1259274.

81. Lean RE, Paul RA, Smyser CD, Rogers CE. Maternal intelligence quotient (IQ) predicts IQ and language in very preterm children at age 5 years. J Child Psychol Psychiatry. 2018 [cited 2019 Jun 13];59(2):150-9. Available from: http://www.ncbi.nlm.nih.gov/pubmed/28925538.

82. Whitley E, Gale CR, Deary IJ, Kivimaki M, Batty GD. Association of maternal and paternal IQ with offspring conduct, emotional, and attention problem scores. Arch Gen Psychiatry. 2011 [cited 2019 Jun 13];68(10):1032. Available from: http://archpsyc.jamanetwork.com/article.aspx?doi=10.1001/ archgenpsychiatry.2011.111.

83. Bird A. Perceptions of epigenetics. Nature. 2007 [cited 2019 Jul 8];447(7143): 396-8. Available from: http://www.nature.com/articles/nature05913.

84. Grafodatskaya D, Chung B, Szatmari P, Weksberg R. Autism spectrum disorders and epigenetics. J Am Acad Child Adolesc Psychiatry. 2010 [cited 2019 Jul 8];49(8):794-809. Available from: https://linkinghub.elsevier.com/ retrieve/pii/S0890856710003916.

85. Channell MM, Thurman AJ, Kover ST, Abbeduto L. Patterns of change in nonverbal cognition in adolescents with Down syndrome. Res Dev Disabil. 2014 [cited 2017 Aug 25];35:2933-41. Available from: http://www.ucdmc ucdavis.edu/mindinstitute/research/abbeduto_lab/publications/patterns-ofchange.pdf.

86. Cycyk LM, Bitetti D, Hammer CS. Maternal depressive symptomatology, social support, and language development of bilingual preschoolers from low-income households. Am J speech-language Pathol. 2015 [cited 2019 Feb 1];24(3):411-25. Available from: http://www.ncbi.nlm.nih.gov/ pubmed/25863774.

87. England MJ, Sim LJ. Depression in parents, parenting, and children: opportunities to improve identification, treatment, and prevention. 2009 [cited 2019 Jun 13]. Available from: http://www.nap.edu/catalog. php?record_id $=12565$.

88. Franke $P$, Maier W, Hautzinger M, Weiffenbach O, Gänsicke M, Iwers B, et al. Fragile-X carrier females: evidence for a distinct psychopathological phenotype? Am J Med Genet. 1996 [cited 2019 Feb 1];64(2):334-9. Available from: http://www.ncbi.nlm.nih.gov/pubmed/8844076.

89. Abbeduto L, Seltzer MM, Shattuck P, Krauss MW, Orsmond G, Murphy MM. Psychological well-being and coping in mothers of youths with autism, down syndrome, or fragile X syndrome. Am J Ment Retard. 2004 [cited 2018 May 8];109(3):237. Available from: http://www.ncbi.nlm.nih.gov/pubmed/15 072518

90. Lewis P, Abbeduto L, Murphy M, Richmond E, Giles N, Bruno L, et al. Psychological well-being of mothers of youth with fragile $X$ syndrome: syndrome specificity and within-syndrome variability. J Intellect Disabil Res. 2006 [cited 2018 Jul 25];50(12):894-904. Available from: http://doi.wiley. com/10.1111/j.1365-2788.2006.00907.x.

91. Bailey DB, Sideris J, Roberts J, Hatton D. Child and genetic variables associated with maternal adaptation to fragile $X$ syndrome: a multidimensional analysis. Am J Med Genet Part A. 2008 [cited 2019 Feb 1]; 146A(6):720-9. Available from: http://www.ncbi.nlm.nih.gov/pubmed/1 8266246.

92. Roberts JE, Bailey DB, Mankowski J, Ford A, Sideris J, Weisenfeld LA, et al. Mood and anxiety disorders in females with the FMR1 premutation. Am J
Med Genet Part B Neuropsychiatr Genet . 2009 [cited 2019 Feb 1];150B(1): 130-9. Available from: http://www.ncbi.nlm.nih.gov/pubmed/18553360,

93. Smith AL, Romski M, Sevcik RA, Adamson LB, Barker RM. Parent stress and perceptions of language development: comparing Down syndrome and other developmental disabilities. Fam Relat. 2014 [cited 2019 Feb 1];63(1): 71-84. Available from: http://www.ncbi.nlm.nih.gov/pubmed/24753637.

94. Hoff E. The specificity of environmental influence: socioeconomic status affects early vocabulary development via maternal speech. Child Dev. 2003 [cited 2019 Feb 1];74(5):1368-78. Available from: http://www.ncbi.nlm.nih. gov/pubmed/14552403.

95. Schwab JF, Lew-Williams C. Language learning, socioeconomic status, and child-directed speech. Wiley Interdiscip Rev Cogn Sci. 2016 [cited 2019 Feb 1];7(4):264-75. Available from: http://www.ncbi.nlm.nih.gov/pubmed/271 96418.

96. Hart B, Risley TR. Meaningful differences in the everyday experience of young American children. [cited 2019 Jul 8]. 268 p. Available from: https:// eric.ed.gov/?id=ED387210.

97. Fernald A, Marchman VA, Weisleder A. SES differences in language processing skill and vocabulary are evident at 18 months. Dev Sci. 2013 [cited 2019 Feb 1];16(2):234-48. Available from: http://www.ncbi.nlm.nih. gov/pubmed/23432833.

98. Noble KG, Engelhardt LE, Brito NH, Mack $L$, Nail EJ, Angal J, et al. Socioeconomic disparities in neurocognitive development in the first two years of life. Dev Psychobiol. 2015 [cited 2019 Feb 1];57(5):535-51. Available from: http://www.ncbi.nlm.nih.gov/pubmed/25828052.

99. Estigarribia B, Martin GE, Roberts JE. Cognitive, environmental, and linguistic predictors of syntax in fragile $X$ syndrome and Down syndrome. J Speech Lang Hear Res. 2012 [cited 2017 Jun 16];55(6):1600. Available from: http:// jslhr.pubs.asha.org/article.aspx?doi=10.1044/1092-4388(2012/10-0153).

100. Couzens D, Haynes M, Cuskelly M. Individual and environmental characteristics associated with cognitive development in Down syndrome: a longitudinal study. J Appl Res Intellect Disabil. 2012 [cited 2016 May 17]; 25(5):396-413. Available from: http://www.ncbi.nlm.nih.gov/pubmed/22 890941.

101. Hunter JE, Allen EG, Shin M, Bean LJH, Correa A, Druschel C, et al. The association of low socioeconomic status and the risk of having a child with Down syndrome: a report from the National Down Syndrome Project. Genet Med. 2013 [cited 2016 Apr 11];15(9):698-705. Available from: http:// www.pubmedcentral.nih.gov/articlerender.fcgi?artid=4122862\&tool= pmcentrez\&rendertype=abstract.

102. Sperry DE, Sperry LL, Miller PJ. Language Does matter: but there is more to language than vocabulary and directed speech. Child Dev. 2019 [cited 2019 Jun 14];90(3):993-7. Available from: https://onlinelibrary.wiley.com/doi/abs/1 $0.1111 /$ cdev. 13125 .

103. Kover ST, Abbeduto L. Expressive language in male adolescents with fragile X syndrome with and without comorbid autism. J Intellect Disabil Res. 2010 [cited 2017 Mar 21];54(3):246-65. Available from: http://www.ncbi.nlm.nih. gov/pubmed/20146742.

104. Thurman AJ, Kover ST, Ted Brown W, Harvey DJ, Abbeduto L. Noncomprehension signaling in males and females with Fragile $X$ syndrome. J Speech Lang Hear Res. 2017 [cited 2018 Jun 11];60(6):1606-21. Available from: http://www.ncbi.nlm.nih.gov/pubmed/28586922.

105. Mayer M. Frog goes to dinner: Dial Press; 1974.

106. Miller J, Iglesias A. Systematic analysis of language transcripts (SALT version 9) [computer software]. Madison: Language Analysis Lab, University of Wisconsin-Madison; 2006.

107. Roid GH, Miller LJ. Leiter Interna- tional Performance Scale-Revised. Wood Dale: Stoelting; 1997.

108. Mervis CB, Klein-Tasman BP. Methodological issues in group-matching designs: a levels for control variable comparisons and measurement characteristics of control and target variables. J Autism Dev Disord. 2004;34:7-17.

109. Kaufman A\& KN. Kaufman brief intelligence test. Second Edi. Circle Pines: American Guidance Service; 2004.

110. Derogatis L. Symptom Checklist 90-R: Administration, scoring, and procedures manual (Third). Baltimore; 1994. Available from: https://www. pearsonclinical.com/psychology/products/100000645/symptom-checklist-90revised-scl-90-r.html.

111. Bengston VL, Black KD. Intergenerational relations and continuities in socialization. In: Life-Span Developmental Psychology. Elsevier; 1973 [cited 2018 May 11]. p. 207-34. Available from: http://linkinghub.elsevier.com/ retrieve/pii/B9780120771509500150. 
112. Hoyo L Del, Xicota L, Sánchez-Benavides G, Cuenca-Royo A, Sola S de, Langohr K, et al. Semantic verbal fluency pattern, dementia rating scores and adaptive behavior correlate with plasma A 42 Concentrations in Down Syndrome Young Adults. Front Behav Neurosci. 2015 [cited 2019 Apr 12];9: 301. Available from: http://journal.frontiersin.org/Article/10.3389/fnbeh.2015. 00301/abstract.

113. McDuffie A, Oakes A, Machalicek W, Ma M, Bullard L, Nelson S, et al. Early language intervention using distance video-teleconferencing: a pilot study of young boys with fragile $X$ syndrome and their mothers. Am J SpeechLanguage Pathol. 2016 [cited 2017 Jun 22];25(1):46. Available from: http:// www.ncbi.nlm.nih.gov/pubmed/26502382.

114. Nelson S, McDuffie A, Banasik A, Tempero Feigles R, Thurman AJ, Abbeduto L. Inferential language use by school-aged boys with fragile $X$ syndrome: Effects of a parent-implemented spoken language intervention. J Commun Disord. 2018 [cited 2018 Jul 5];72:64-76. Available from: https://www. sciencedirect.com/science/article/pii/S0021992417300904?via\%3Dihub.

115. Hogan-Brown AL, Losh M, Martin GE, Mueffelmann DJ. An investigation of narrative ability in boys with autism and fragile X syndrome. Am J Intellect Dev Disabil. 2013 [cited 2017 Jun 21];118(2):77-94. Available from: http:// www.ncbi.nlm.nih.gov/pubmed/23464607.

116. Sterling A, Abbeduto L. Language development in school-age girls with fragile X syndrome. J Intellect Disabil Res. 2012 [cited 2018 Apr 26];56(10): 974-83. Available from: http://www.ncbi.nlm.nih.gov/pubmed/22676254.

117. Abbeduto L, McDuffie A, Thurman AJ. The fragile x syndrome-autism comorbidity: what do we really know? Front Genet. 2014 [cited 2017 Aug 25];5(SEP). Available from: http://www.ucdmc.ucdavis.edu/mindinstitute/ research/abbeduto_lab/publications/abbeduto-frontiers.pdf.

118. Hahn $L$, Brady NC, Warren SF, Fleming KK. Do children with fragile $X$ syndrome show declines or plateaus in adaptive behavior? Am J Intellect Dev Disabil. 2015 [cited 2018 Jun 20];120(5):412-32. Available from: http:// www.ncbi.nlm.nih.gov/pubmed/26322389.

119. Lott I. Neurological phenotypes for Down syndrome across the life span. Prog Brain Res. 2012 [cited 2015 Nov 10];197:101-21. Available from: http:// www.pubmedcentral.nih.gov/articlerender.fcgi?artid $=34178248$ tool $=$ pmcentrez\&rendertype=abstract.

\section{Publisher's Note}

Springer Nature remains neutral with regard to jurisdictional claims in published maps and institutional affiliations.

Ready to submit your research? Choose BMC and benefit from:

- fast, convenient online submission

- thorough peer review by experienced researchers in your field

- rapid publication on acceptance

- support for research data, including large and complex data types

- gold Open Access which fosters wider collaboration and increased citations

- maximum visibility for your research: over $100 \mathrm{M}$ website views per year

At $\mathrm{BMC}$, research is always in progress.

Learn more biomedcentral.com/submissions 